\title{
Dopant Selection Strategy for High Quality Factor Localized Surface Plasmon Resonance from Doped Metal Oxide Nanocrystals
}

\author{
Bharat Tandon ${ }^{\dagger}$, Sandeep Ghosh ${ }^{\dagger}$, and Delia J. Milliron ${ }^{\dagger *}$ \\ ${ }^{\dagger}$ McKetta Department of Chemical Engineering, The University of Texas at Austin, Austin, Texas 78712-1589, United States \\ *Department of Chemistry, Indian Institute of Science Education and Research, Dr. Homi Bhabha Road, Pune-411008, India
}

\begin{abstract}
Thin films of degenerately doped metal oxides such as those of Sn-doped $\operatorname{In}_{2} \mathrm{O}_{3}\left(\mathrm{Sn}_{2} \operatorname{In}_{2} \mathrm{O}_{3}\right)$ are commercially significant for their broad utilization as transparent conducting electrodes in optoelectronic devices. Over the last decade, nanocrystals (NCs) of $\mathrm{Sn}: \mathrm{In}_{2} \mathrm{O}_{3}$ and other doped metal oxides have also attracted interest for localized surface plasmon resonance (LSPR) that occurs in the near to mid-infrared region. The suitability of this LSPR for some applications depends on its capacity to concentrate light in small regions of space, known as near-field hot spots. This efficiency to create near-field hot spots can be judged through an LSPR figureof-merit such as Quality factor, defined as the ratio of LSPR peak energy to its linewidth. The free electron density determines the LSPR peak energy while the extent of electron scattering controls the LSPR linewidth and hence these factors together essentially dictate the value of the Quality factor. An unfortunate tradeoff arises when dopants are introduced since the aliovalent dopants generating the free electrons (increasing LSPR energy) also act as centers of scattering of electrons (increasing LSPR linewidth), thereby decreasing the LSPR Quality factor. Dopant selection is hence of paramount importance to achieve a high value of LSPR Quality factor. Here, we describe the properties of aliovalent cationic dopants that allow both high LSPR energy and low LSPR linewidth and, subsequently, high LSPR Quality factor. In this context, we identify $\mathrm{Zr}^{4+}$ as a model aliovalent dopant for high LSPR Quality factor in the $\mathrm{In}_{2} \mathrm{O}_{3}$ lattice. The resulting $\mathrm{Zr}$-doped $\operatorname{In}_{2} \mathrm{O}_{3} \mathrm{NCs}$ exhibit one of the highest LSPR Quality factors reported in the mid-infrared region while also performing equivalently to the recognized materials for either high dopant activation $\left(\mathrm{Sn}: \mathrm{In}_{2} \mathrm{O}_{3} \mathrm{NCs}\right)$ or low LSPR linewidth (Ce-doped $\mathrm{In}_{2} \mathrm{O}_{3} \mathrm{NCs}$ ), simultaneously. The $\mathrm{Zr}$ donor level is positioned well into the conduction band of $\mathrm{In}_{2} \mathrm{O}_{3}$ and $\mathrm{Zr}$ doping is surface segregated, both minimizing electron scattering. The combination of this low electron scattering and high dopant activation of $\mathrm{Zr}^{4+}$ ions is responsible for the high LSPR Quality factors. These strategies can be used to design a variety of doped metal oxide NC systems exhibiting high LSPR Quality factors.
\end{abstract}

Thin films of degenerately doped metal oxides have been long utilized as transparent conducting electrodes in solar cells and photovoltaics due to their unusual ability to combine the properties of visible light transparency and high electrical conductivity in one material. ${ }^{1}$ Owing to the same free electron properties, nanocrystals (NCs) of such degenerately doped metal oxides also exhibit mid- to near-infrared localized surface plasmon resonance (LSPR). ${ }^{2-7}$ The LSPR response is induced by the generation of free charge carriers (electrons in case of $n$ doped metal oxides discussed here), which collectively oscillate at resonant frequencies. These LSPR active NCs may find applications in sensing, ${ }^{8-10}$ photothermal therapy, ${ }^{11}$ photovoltaics, ${ }^{12}$ electrochromic coatings, ${ }^{13-15}$ and advanced spectroscopies such as surface enhanced infrared absorption (SEIRA). ${ }^{3}$ For many of these potential applications, the potential of these NCs to create intense localized electric fields (hot spots) around them is essential. In general, LSPR excitations can effectively focus electric fields into volumes well below the diffraction limit, but this is not yet well established for doped metal oxide materials. The potential efficiency of hot spot generation can be assessed indirectly by a figure of merit derived from the LSPR response known as the Quality factor (or Q-factor), which is defined as the ratio of the LSPR peak energy to its full width at half maximum (FWHM). LSPR peak energy depends on the free carrier density in the
NCs, while the FWHM reflects the extent of carrier scattering, e.g., by charged point defects in the $\mathrm{NC}$ lattice. ${ }^{16}$ Consequently, a high Q-factor suggests stronger near-field enhancements, longer plasmon lifetimes, and weaker electronic damping. Hence, it becomes important to consider two significant impacts of dopants in metal oxide NCs: (a) changing free electron density leading to tuning of the LSPR energy, and (b) scattering the motion of oscillating free electrons leading to damping of the LSPR.

In some cases, the relatively high value of the high-frequency dielectric constant of the host material enables unusually high LSPR Q-factors, through shielding the electrostatic interactions between the dopants and the electrons. This is generally the case for doped $\mathrm{CdO},{ }^{17}$ such as NCs of In-doped $\mathrm{CdO},{ }^{18}$ and $\mathrm{F}$,Incodoped CdO. ${ }^{19}$ Regardless of the dielectric characteristics of the host material, a high LSPR Q-factor can conceivably be engineered based on the selection of the aliovalent dopant. For instance, $\mathrm{Sn}^{4+}$ is a shallow donor in $\mathrm{In}_{2} \mathrm{O}_{3}$, donating electrons to the conduction band of $\operatorname{In}_{2} \mathrm{O}_{3}$ and increasing the LSPR energy. ${ }^{20-22}$ However, apart from acting as ionized donor impurities, Sn dopants in $\mathrm{In}_{2} \mathrm{O}_{3}$ also hybridize with In $5 \mathrm{~s}$ orbitals, leading to significant renormalization of the band curvature at the conduction band minimum, ${ }^{23-25}$ thereby changing the effective mass, increasing the LSPR FWHM, and decreasing the electron mobility. ${ }^{16}$ Cerium is an alternative 
dopant for $\operatorname{In}_{2} \mathrm{O}_{3}$ or a co-dopant with $\mathrm{Sn}$ that has been reported to minimize ionized impurity scattering. $\mathrm{Ce}^{4+}$ introduces defect states deep in the conduction band of $\mathrm{In}_{2} \mathrm{O}_{3}$, well away from the conduction band edge, leading to a narrow LSPR FWHM. Unfortunately, $\mathrm{Ce}^{4+}$ is readily reduced to $\mathrm{Ce}^{3+}$, so dopant activation is low, especially at higher dopant concentrations, and the LSPR energy achievable by this strategy is limited. ${ }^{26} \mathrm{In}$ each case - either $\mathrm{Sn}$ and Ce-doped $\mathrm{In}_{2} \mathrm{O}_{3} \mathrm{NCs}-$ one attribute of the dopant substantially limits the LSPR Q-factor and yet these materials still exhibit among the highest Q-factor values in the near-infrared. There is a potential to enhance LSPR Qfactor further through a combination of high LSPR energy and low LSPR FWHM. Achieving this requires identification of dopants through their fundamental properties which will simultaneously increase LSPR energy and diminish FWHM as dopants interact with the crystal lattice, ultimately leading to high LSPR Q-factors.

The LSPR frequency $\omega_{L S P R}$ can be described by equation (1)

$$
\omega_{L S P R}=\sqrt{\frac{\omega_{P}^{2}}{\left(\varepsilon_{\infty}+2 \varepsilon_{m}\right)}-\gamma^{2}}
$$

where $\varepsilon_{\infty}$ is the high frequency dielectric constant of the material, $\varepsilon_{m}$ is the dielectric constant of the medium surrounding the NCs, and $\gamma$ is the damping constant. Since, $\varepsilon_{\infty}$ is a characteristic property of the material that isn't expected to change with doping and $\varepsilon_{m}$ is fixed by the environment (the solvent in the case of dispersed NCs), the controllable parameters with a strong influence on the LSPR frequency are the damping constant (that determines LSPR FWHM) and the bulk plasma frequency $\omega_{P}$ which is given by,

$$
\omega_{p}^{2}=\frac{n e^{2}}{\varepsilon_{0} m^{*}}
$$

where $n$ is the free carrier density, $e$ is the electronic charge, $\varepsilon_{o}$ is the permittivity of air/vacuum, and $m^{*}$ is the effective mass of the free charge carriers (electrons or holes). ${ }^{27}$ Since $e$ and $\varepsilon_{o}$ are constants, the LSPR energy is directly dependent on the carrier density and the effective carrier mass. In this regard, two scenarios can be envisaged when it comes to generating free charge carrier density by a cationic substitutional doping in metal oxides: (a) when the dopant level exists close to the conduction band minimum (shallow donor), and (b) when the dopant states reside well inside the conduction band of the host. As an example of the first scenario, a shallow donor (such as $\mathrm{Sn}$ in $\mathrm{In}_{2} \mathrm{O}_{3}$ ) hybridizes with the conduction band minimum triggering renormalization of conduction band curvature and therefore a flatter band with higher effective carrier mass is obtained. ${ }^{28}$ This hybridization leads to a lower $\omega_{P}$ and hence, a donor level inside the conduction band is preferred over a shallow donor for generation of free electrons and raising of $\omega_{P} \cdot{ }^{26,28-29}$ Additionally, the generation of free electrons can be hindered if the dopant exhibits multiple stable oxidation states, if electron acceptors are present, ${ }^{26,30-33}$, or if defect clusters introduce electron trapping sites. ${ }^{23,34-36}$ These compensation effects are highly undesirable as they decrease the dopant activation (number of electrons generated per dopant). One can estimate the feasibility of change in oxidation state through the standard reduction potentials. Metal ions exhibiting multiple oxidation states with large positive values of standard reduction potentials are not likely to perform as ideal dopants for generation of high electron density. For example, the standard reduction potential for reduction of $\mathrm{Ce}^{4+}$ to $\mathrm{Ce}^{3+}$ is $+1.44 \mathrm{~V}$ as a result of which $\mathrm{Ce}^{4+}$ doping in $\mathrm{In}_{2} \mathrm{O}_{3}$ suffers from the problem of low dopant activation. ${ }^{26}$
The damping constant $\gamma$ is a reflection of electron scattering, though the scattering mechanisms that are dominant for noble metal nanoparticles - including electron-electron, and electronphonon scattering - which are not necessarily the dominant electron scattering mechanisms in doped metal oxide NCs. When the size of a NC becomes much smaller than the bulk mean free path of carrier in a material, surface scattering can be significant. ${ }^{37}$ At all sizes, electrostatic interactions between the dopant ions and the electrons can significantly impact scattering in doped metal oxide NCs. This phenomenon is known as ionized impurity scattering, ${ }^{16}$ and the LSPR FWHM can be limited by the strength of this electrostatic interaction, which can be described by the Lewis acidity of the dopant. According to the quantitative description given by Zhang et al., ${ }^{38}$ the Lewis acidity $L$ of an ion is expressed as,

$$
L=\frac{Z}{r^{2}}-7.7 \chi+8.0
$$

where $Z$ is the charge on an ion, $r$ is the radius of the ion and $\chi$ is the electronegativity of the element. A stronger Lewis acid (large L) will, therefore, be a better aliovalent dopant than a weaker one. This is because, a high charge to radius ratio polarizes the electron cloud of the oxygen more strongly, reducing its capability as a scattering center. On the other hand, a smaller electronegativity value than the host cation ensures that the interactions between the free electrons and dopant cations are minimized. In terms of electronic band structure, this means that the dopant levels lie higher in energy than the conduction band minimum of the host lattice. Owing to this alignment, $\mathrm{Ce}$, which has a low electronegativity value, leads to much larger L value (smaller LSPR FWHM) than Sn, ${ }^{21,26}$ in $\mathrm{In}_{2} \mathrm{O}_{3}$ despite $\mathrm{Sn}$ exhibiting a higher charge to radius ratio. ${ }^{39}$ Hence, to obtain a low LSPR FWHM in $\mathrm{In}_{2} \mathrm{O}_{3} \mathrm{NCs}$, a dopant with a charge-to-radius ratio greater than In and an electronegativity value smaller than In is desired. However, a large change in charge to radius ratio with respect to the host cation can also produce significant lattice strain in the host lattice and may even induce formation of a secondary phase.

In consideration of the above, $\mathrm{Zr}^{4+}$ appears to be a compelling candidate as a dopant in $\operatorname{In}_{2} \mathrm{O}_{3}$. $\mathrm{Zr}$ is almost always found in the +4 oxidation state (standard reduction potential $\mathrm{Zr}^{4+} / \mathrm{Zr}=-1.45$ $\mathrm{V}$ ), which makes it an aliovalent dopant in the $\operatorname{In}_{2} \mathrm{O}_{3}$ lattice $\left(Z r_{\text {In }}\right)$. Recent calculations by $\mathrm{Xu}$ et al. have shown that donor levels for $\mathrm{Zr}$ lie deep inside the conduction band of $\mathrm{In}_{2} \mathrm{O}_{3}$ (which can be ascribed largely to its lower electronegativity than In) and proposed it to be a prospective dopant of choice for high mobility transparent conducting oxides. ${ }^{28}$ The occurrence of $\mathrm{Zr}$ donor levels deep inside the conduction band means that the curvature of conduction band minimum is not expected to be affected by doping and electrons donated will have a low carrier effective mass close to the $0.22 \mathrm{~m}_{\mathrm{e}}$ of the parent $\mathrm{In}_{2} \mathrm{O}_{3}$ material. Moreover, the ionic radius of $\mathrm{Zr}^{4+}(74 \mathrm{pm})$ matches closely with that of $\mathrm{In}^{3+}(79 \mathrm{pm})$ signifying that no significant lattice strain is anticipated from the substitution of In with $\mathrm{Zr}$ while sustaining a higher charge-to-radius ratio than $\mathrm{In} .{ }^{40} \mathrm{We}$, therefore, hypothesized that $\mathrm{Zr}$ doping in $\mathrm{In}_{2} \mathrm{O}_{3} \mathrm{NCs}$ could lead to a high Q-factor LSPR with high dopant activation and low FWHM, which would also imply an increased mobility of electrons. Prior experimental reports showing high electron mobilities in $\mathrm{Zr}$-doped $\mathrm{In}_{2} \mathrm{O}_{3}$ thin films, ${ }^{41-43}$ encouraged us to develop a synthesis for $\mathrm{Zr}$-doped $\mathrm{In}_{2} \mathrm{O}_{3}\left(\mathrm{Zr}: \operatorname{In}_{2} \mathrm{O}_{3}\right) \mathrm{NCs}$ and examine their mettle as an LSPR active material.

We report here the colloidal synthesis of $\mathrm{Zr}: \operatorname{In}_{2} \mathrm{O}_{3} \mathrm{NCs}$, by a procedure involving alcoholysis of metal carboxylates. ${ }^{44-45}$ In 
brief, using standard Schlenk line techniques operating under inert $\mathrm{N}_{2}$ atmosphere, $8 \mathrm{~mL}$ of $0.5 \mathrm{M}$ mixture of $\mathrm{In}$ and $\mathrm{Zr}$ precursors, Indium(III) acetate and zirconium(IV) acetylacetonate, respectively, were dissolved in oleic acid at $150^{\circ} \mathrm{C}$. A mixture of these was injected at a rate of $0.2 \mathrm{~mL} / \mathrm{min}$ into $13 \mathrm{~mL}$ of oleyl alcohol held at $290^{\circ} \mathrm{C}$. After the reaction, the solution was cooled down and the resultant NCs were washed with ethanol and dispersed in different nonpolar solvents for further characterization. The synthesis and characterization details are described in Sections S1 and S2 of the supporting information, respectively. The doping percentages reported herein were obtained using inductively coupled plasma optical emission spectroscopy (ICP-OES).

The structure of the NCs was assessed by x-ray diffraction (XRD, Figure 1a). At all dopant concentrations, the NCs have the same cubic bixbyite structure as the parent $\operatorname{In}_{2} \mathrm{O}_{3}$ and no impurity peaks are present. Moreover, as the $\mathrm{Zr}$ doping percentage is increased, the diffraction peaks first shift to higher $2 \theta$ values (signifying a decrease in the lattice constant) and then shift back to smaller $2 \theta$ values suggesting an interplanar distance similar to undoped $\operatorname{In}_{2} \mathrm{O}_{3}$ NCs (Figure 1b). The ionic radius of $\mathrm{Zr}^{4+}$ is smaller than that of $\mathrm{In}^{3+},{ }^{40}$ which could be expected to lead to a gradual decrease in the lattice constant with an increase in $\mathrm{Zr}$ doping percentage, in accordance with Vegard's law. ${ }^{46}$ The observed trend is more complex since the lattice constant increases as doping percentages above $1.5 \%$. However, similar trends have routinely been reported in doped metal oxides and, in particular in $\mathrm{Sn}: \operatorname{In}_{2} \mathrm{O}_{3}$, where the lattice expansion is attributed to the repulsion between the $\mathrm{Sn}^{4+}$ ions which cannot be compensated entirely by the electron density in the lattice. ${ }^{22,}{ }^{47-48} \mathrm{We}$ suggest that a similar mechanism is underlying the trend reported here with $\mathrm{Zr}^{4+}$ ions incorporated in the $\mathrm{In}_{2} \mathrm{O}_{3}$ lattice across the range of compositions we synthesized, with competing factors influencing the lattice constant. Our understanding that $\mathrm{Zr}$ is well incorporated in the lattice is further substantiated by the systematic increase in the FWHM of the XRD peaks with an increase in $\mathrm{Zr}$ doping signifying a systematic decrease in the crystallite size with $\mathrm{Zr}$ doping. We note here that inhomogeneous strain in the NCs can also broaden the XRD peaks, but it is unlikely to follow a systematic trend with $\mathrm{Zr}$ doping. We complemented the XRD analysis with Raman spectroscopy to assess the potential formation of any amorphous or impurity phases (Figure 1c). Regardless of $\mathrm{Zr}$ dopant concentration, the $\mathrm{Zr}: \mathrm{In}_{2} \mathrm{O}_{3} \mathrm{NCs}$ exhibit the same phonon modes as undoped $\mathrm{In}_{2} \mathrm{O}_{3} \mathrm{NCs}$, suggesting that no significant amorphous or crystalline impurity phases are present. ${ }^{31,49-50}$ The trend of XRD peak widths suggesting a decrease in $\mathrm{NC}$ size with an increase in $\mathrm{Zr}$ doping percentage is confirmed by direct observations using scanning transmission electron microscopy (STEM) (Figures 1d-e, S1, and S2).The high resolution TEM images in Figure 1f show the single crystalline nature of $\mathrm{Zr}: \operatorname{In}_{2} \mathrm{O}_{3} \mathrm{NCs}$ and interplanar distances corresponding to different lattice planes in the cubic bixbyite structure, further confirming the crystalline structure of the synthesized NCs.
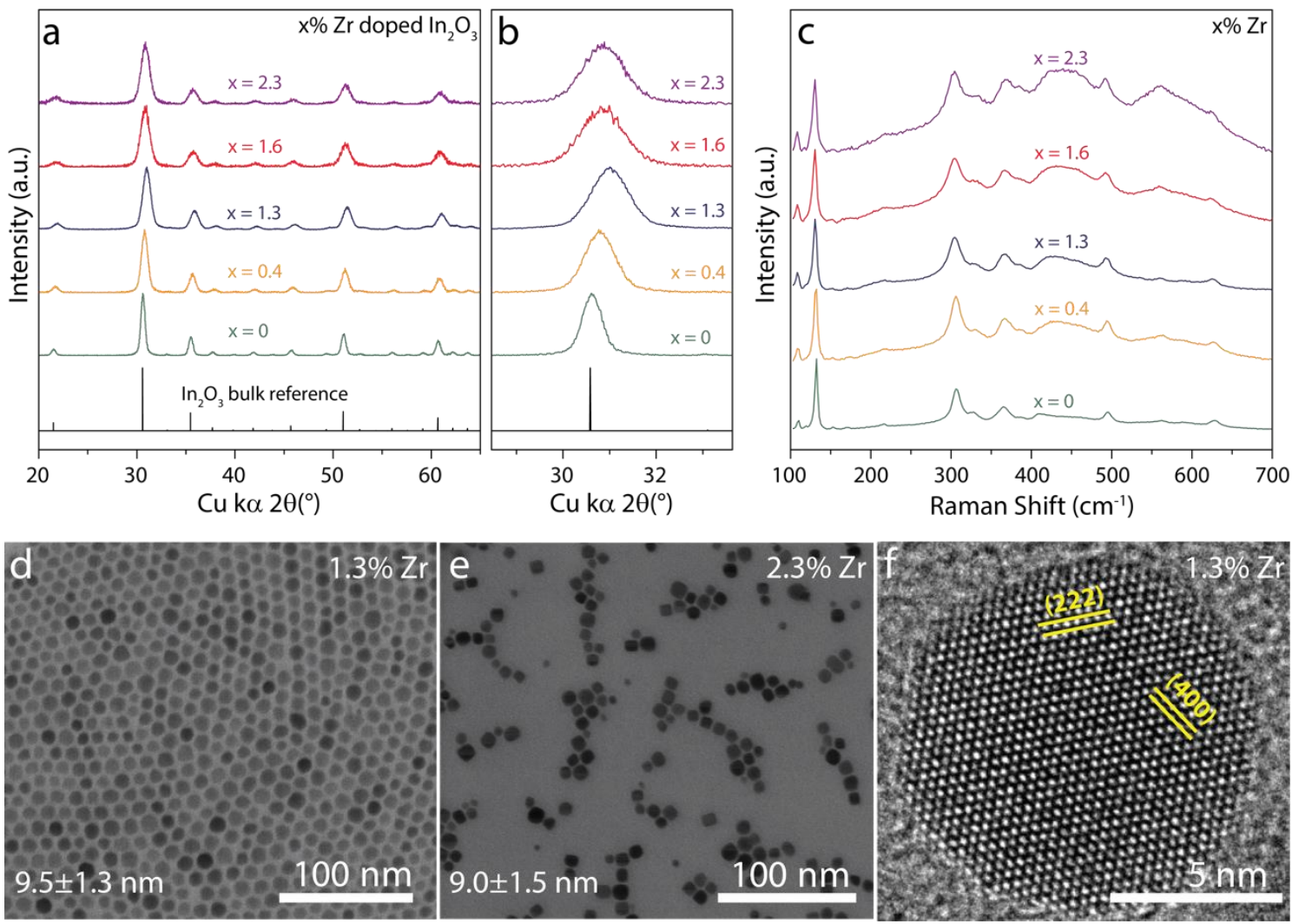

Figure 1: Characterization of $\mathrm{Zr}: \mathrm{In}_{2} \mathrm{O}_{3} \mathrm{NCs}$ (a) comparison of XRD patterns with bulk $\mathrm{In}_{2} \mathrm{O}_{3}$ reference (JCPDS 88-2160) indicating retention of the cubic bixbyite structure across doping concentrations (b) shift in the XRD peaks with incorporation of $\mathrm{Zr}^{4+}$ ions (c) $\mathrm{Raman}$ spectroscopy signifying absence of any impurity phase, amorphous or crystalline (d,e) STEM images showing nearly spherical NCs with narrow size distribution (f) High resolution TEM image showing the single crystalline nature of the NCs, with interplanar distances corresponding to different planes in the $\mathrm{In}_{2} \mathrm{O}_{3}$ structure.

To ascertain the oxidation state of the $\mathrm{Zr}$ ions in the $\mathrm{In}_{2} \mathrm{O}_{3}$ NCs, we employed X-ray photoelectron spectroscopy (XPS) on all the $\mathrm{Zr}: \mathrm{In}_{2} \mathrm{O}_{3} \mathrm{NCs}$ and plotted the obtained spectra in the $\mathrm{Zr}$ $3 \mathrm{~d}$ region (Figure $2 \mathrm{a}$ ). $\mathrm{Zr} 3 \mathrm{~d}_{5 / 2}$ and $\mathrm{Zr} 3 \mathrm{~d}_{3 / 2}$ binding energy peaks 
located at $182.3 \mathrm{eV}$ and $184.7 \mathrm{eV}$, correspond to $\mathrm{Zr}$ in the +4 oxidation state, ${ }^{51-52}$ progressively increasing in intensity with an increase in the $\mathrm{Zr}$ doping. The spectra could be fit using only one component, which further indicates the presence of $\mathrm{Zr}$ in a single oxidation state.

To determine the radial distribution of $\mathrm{Zr}$ in the $\mathrm{NC}$, we compared the doping percentages obtained from XPS and ICPOES. XPS gives an estimation of the surface doping percentage whereas ICP-OES is a measure of overall NC composition (surface and core). Doping percentages obtained from XPS are significantly greater those from ICP-OES (Figure 2b) suggesting that $\mathrm{Zr}$ is slightly surface segregated or in other words, $\mathrm{Zr}^{4+}$ ions preferentially substitute at In sites nearer the surface of the NCs. Although the precise mechanism responsible for surface segregation of $\mathrm{Zr}$ dopants could not be elucidated, we hypothesize that using precursors with different reactivity (indium(III) acetate, a highly reactive In precursor versus the only moderately reactive $\mathrm{Zr}$ precursor, zirconium(IV) acetylacetonate) alters the kinetics of incorporation of $\mathrm{In}$ and $\mathrm{Zr}$ ions during $\mathrm{NC}$ growth and ultimately effects the radial distribution of dopants. ${ }^{53}$ Surface segregated doping can be favorable as previous work has shown it is associated with narrow LSPR and high Q-factors. ${ }^{21-22,54}$ Dopants segregated near the surface allow charge carriers to move inside the lightly doped or undoped NC core without scattering from ionized impurities. The reduced scattering minimizes LSPR damping, thereby decreasing the LSPR FWHM and enhancing electron mobility.

All the $\mathrm{Zr}$ : $\mathrm{In}_{2} \mathrm{O}_{3} \mathrm{NCs}$ show remarkably narrow LSPR absorption with their LSPR energies monotonically increasing with an increase in $\mathrm{Zr}$ dopant concentration, signifying the donor behavior of $\mathrm{Zr}^{4+}$ ions (Figures 3 and S3). The LSPR of undoped $\operatorname{In}_{2} \mathrm{O}_{3} \mathrm{NCs}$ is attributed to the accumulation of electron density due to oxygen vacancies whereas in $\mathrm{Zr}: \mathrm{In}_{2} \mathrm{O}_{3} \mathrm{NCs}, \mathrm{Zr}$ doping is largely responsible for compensating the free electrons. The highly symmetric shapes of the LSPR peaks in Figure 3 indicates there is little ionized impurity scattering, ${ }^{16}$, 21-22, 27 consistent with our initial hypothesis. The LSPR parameters of different $\mathrm{Zr}: \mathrm{In}_{2} \mathrm{O}_{3} \mathrm{NCs}$ are listed in Table ST1. Quantitatively, the LSPR FWHM of $735 \mathrm{~cm}^{-1}(91 \mathrm{meV})$ for $1.3 \% \mathrm{Zr}: \mathrm{In}_{2} \mathrm{O}_{3} \mathrm{NCs}$ is very close to that reported for $\mathrm{Ce}$-doped $\mathrm{In}_{2} \mathrm{O}_{3} \mathrm{NCs}(77 \mathrm{meV}),{ }^{26}$ In-doped $\mathrm{CdO}(67 \mathrm{meV})^{18}$ and smaller than the lowest reported LSPR FWHM for $\mathrm{Sn}: \mathrm{In}_{2} \mathrm{O}_{3}(99 \mathrm{meV})^{22}$ and other doped metal oxide NCs (Table ST2); hence $\mathrm{Zr}: \mathrm{In}_{2} \mathrm{O}_{3}$ NCs exhibit one of the narrowest LSPR peaks yet reported. In terms of LSPR Q-factor, $\mathrm{Zr}: \mathrm{In}_{2} \mathrm{O}_{3} \mathrm{NCs}$ display rather high values over a range of LSPR energies that are almost identical to those of Ce-doped $\mathrm{In}_{2} \mathrm{O}_{3} \mathrm{NCs}$ and subsequently, one of the highest in the literature. Electron concentrations achievable with $\mathrm{Ce}$ doping are limited by the stability of the $\mathrm{Ce}^{3+}$ ion, which is increasingly preferred as compared to $\mathrm{Ce}^{4+}$ at high doping percentages, thereby reducing the dopant activation. Consequently, the LSPR in Ce-doped $\mathrm{In}_{2} \mathrm{O}_{3} \mathrm{NCs}$ was tunable only over a narrow range at low energy. ${ }^{26}$ Therefore, $\mathrm{Zr}: \mathrm{In}_{2} \mathrm{O}_{3}$ $\mathrm{NCs}$ are a more tunable option for applications where high LSPR Q-factors are desirable.
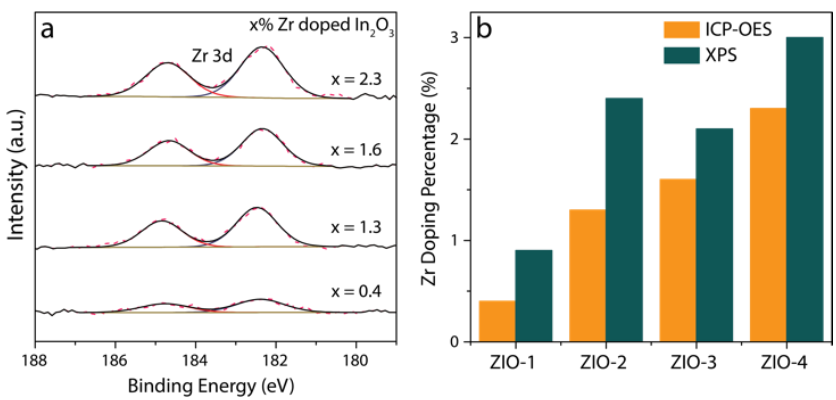

Figure 2: Dopant oxidation state and radial distribution (a) XPS of the $\mathrm{Zr} 3 \mathrm{~d}$ region for different $\mathrm{Zr}: \mathrm{In}_{2} \mathrm{O}_{3} \mathrm{NCs}$ with single component fits (black) to the experimental spectra (pink) shown (b) Comparison of ICP-OES and XPS doping percentages revealing that $\mathrm{Zr}$ doping is surface segregated as doping percentages obtained for surface (XPS) is more than the overall NC composition (ICPOES).The notations $\mathrm{ZIO}-1$ to $\mathrm{ZIO}-4$ on the $\mathrm{x}$-axis just represents $\mathrm{NCs}$ with 4 different $\mathrm{Zr}$ doping percentages.

In addition to observing low LSPR FWHM and high Q-factors, we investigated dopant activation in $\mathrm{Zr}: \mathrm{In}_{2} \mathrm{O}_{3} \mathrm{NCs}$, which is a measure of the extent of electron density accumulation for a given doping percentage. Dopant activation is generally high in $\mathrm{NCs}$ of the prototypical doped metal oxide material $\mathrm{Sn}: \mathrm{In}_{2} \mathrm{O}_{3}$ $\mathrm{NCs},{ }^{21-22,54}$ owing to shallow $\mathrm{Sn}$ donor levels in proximity to the conduction band minimum of $\operatorname{In}_{2} \mathrm{O}_{3}$.

To evaluate the efficacy of $\mathrm{Zr}^{4+}$ as an electron donor, we designed three different comparisons with Sn. Series-1 compares LSPR spectra of $\mathrm{Zr}: \mathrm{In}_{2} \mathrm{O}_{3}$ and $\mathrm{Sn}: \mathrm{In}_{2} \mathrm{O}_{3}$ NCs with similar doping percentages. Series- 2 compares LSPR spectra at a fixed doping percentage achieved through (i) only $\mathrm{Zr}$ doping (ii) only Sn doping (iii) $\mathrm{Zr}$ and $\mathrm{Sn}$ codoping. Series-3 measures the effect of small amounts of $\mathrm{Zr}$ codoping on LSPR spectra of different $\mathrm{Sn}: \mathrm{In}_{2} \mathrm{O}_{3}$ NCs. The characterization data for these NCs (XRD and STEM images along with size distribution histograms) are given in Figure S4-S6. The optical extinction spectra obtained from these series are plotted in Figure 4 and their respective LSPR parameters are tabulated in Table ST1.

Series-1 compares optical extinction spectra of $\mathrm{Zr}: \mathrm{In}_{2} \mathrm{O}_{3} \mathrm{NCs}$ and $\mathrm{Sn}: \mathrm{In}_{2} \mathrm{O}_{3} \mathrm{NCs}$ at two different doping percentages, small $(\sim 0.5 \%)$ and intermediate $(\sim 2.5 \%)$ (Figure $4 \mathrm{a}) . \mathrm{Zr}: \operatorname{In}_{2} \mathrm{O}_{3} \mathrm{NCs}$ have higher peak LSPR energy than $\mathrm{Sn}: \mathrm{In}_{2} \mathrm{O}_{3} \mathrm{NCs}$ at small doping percentage. However, at intermediate doping percentage, the $\mathrm{Sn}: \mathrm{In}_{2} \mathrm{O}_{3} \mathrm{NCs}$ have a higher LSPR energy than $\mathrm{Zr}: \mathrm{In}_{2} \mathrm{O}_{3} \mathrm{NCs}$, potentially due to the difference in the doping level in those two samples. Nonetheless, for both doping levels, the LSPR energies for $\mathrm{Zr}$ and $\mathrm{Sn}$ are in the same range, indicating that both of them have similar donor efficiency. The difference, however, lies in the shape and FWHM of the LSPR. For similar doping percentages, the LSPR of $\mathrm{Zr}: \mathrm{In}_{2} \mathrm{O}_{3} \mathrm{NCs}$ is highly symmetric compared to the asymmetric peaks of $\mathrm{Sn}: \mathrm{In}_{2} \mathrm{O}_{3} \mathrm{NCs}$. Additionally, the LSPR of the $\mathrm{Zr}: \mathrm{In}_{2} \mathrm{O}_{3} \mathrm{NCs}$ is at least $20 \%$ narrower than that of $\mathrm{Sn}_{2} \mathrm{In}_{2} \mathrm{O}_{3}$ NCs (Table ST1), which is reflected in the significantly higher LSPR Q-factors of $\mathrm{Zr}: \mathrm{In}_{2} \mathrm{O}_{3} \mathrm{NCs}$ than $\mathrm{Sn}: \mathrm{In}_{2} \mathrm{O}_{3}$ NCs. Unfortunately, we could not achieve higher doping concentration with $\mathrm{Zr}$ doping because of the low solubility limit of $\mathrm{Zr}$ in $\mathrm{In}_{2} \mathrm{O}_{3} .{ }^{43} \mathrm{NCs}$ are sometimes able to surpass the bulk solubility limit, but even after repeated trials using different $\mathrm{Zr}$ and In precursors, we were in this case not successful at increasing the doping concentration further. ${ }^{55}$ 


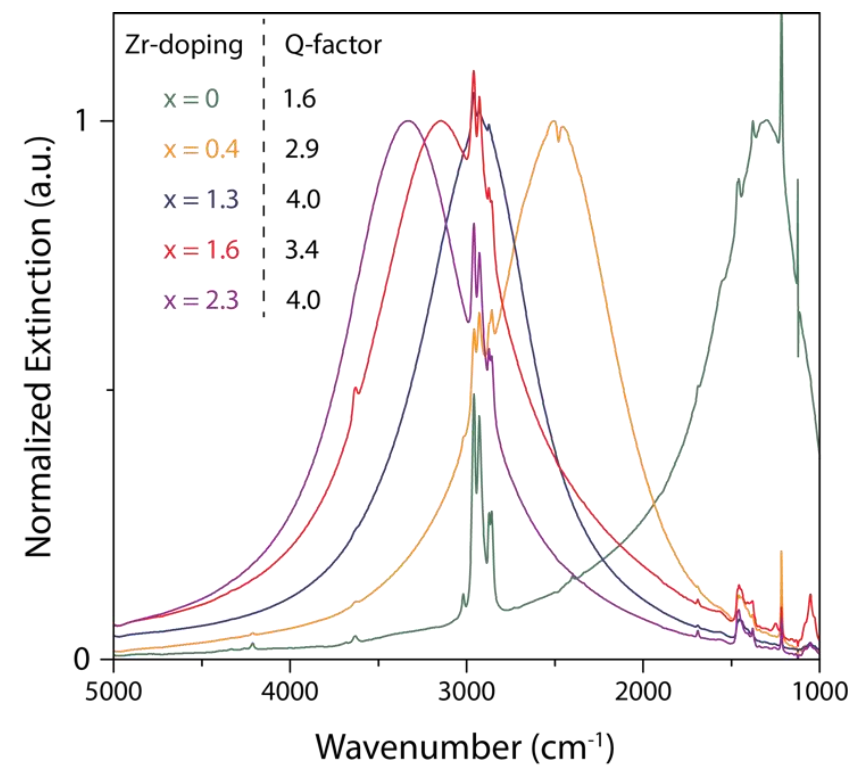

Figure 3: Optical extinction spectra of different $\mathrm{Zr}: \operatorname{In}_{2} \mathrm{O}_{3} \mathrm{NCs}$ displaying narrow and symmetric LSPR bands increasing in energy with an increase in $\mathrm{Zr}$ doping. Spectra were taken by FTIR of NCs dispersed in tetrachloroethylene.

Series-2 compared NCs with similar overall doping percentage $(\sim 2.5 \%)$, but different dopant composition either (i) $2.3 \% \mathrm{Zr}$ doping, (ii) $2.8 \% \mathrm{Sn}$ doping, or (iii) $1.9 \% \mathrm{Sn}-0.9 \% \mathrm{Zr}$ codoping in $\mathrm{In}_{2} \mathrm{O}_{3} \mathrm{NCs}$. The purpose was to assess how the LSPR Q-factor depends on the nature of the dopants. The LSPR energies are almost equivalent for the various dopant combinations, but the LSPR FWHM of $\mathrm{Zr}: \operatorname{In}_{2} \mathrm{O}_{3}$ and $\mathrm{Sn}, \mathrm{Zr}: \mathrm{In}_{2} \mathrm{O}_{3}$ NCs is much smaller than that observed for $\mathrm{Sn}: \mathrm{In}_{2} \mathrm{O}_{3}$ NCs (Figure 4b). In fact, as listed in Table ST1, the LSPR FWHM of $1.9 \% \mathrm{Sn}-0.9 \% \mathrm{Zr}$ codoped $\mathrm{In}_{2} \mathrm{O}_{3} \mathrm{NCs}$ is almost half of that of $2.8 \% \mathrm{Sn}: \mathrm{In}_{2} \mathrm{O}_{3} \mathrm{NCs}$. Consequently, there is a 50\% enhancement in the LSPR Q-factor for the former compared to the latter. The Q-factor of 5.3 for $1.9 \% \mathrm{Sn}-0.9 \%$ $\mathrm{Zr}$ codoped $\mathrm{In}_{2} \mathrm{O}_{3} \mathrm{NCs}$ is the highest Q-factor reported in the mid-infrared region and rivals the Q-factors of even the best performing materials in near-infrared LSPR literature (Table ST2). Both Series-1 and Series-2 are thus strong indicators of the advantages of $\mathrm{Zr}$ over $\mathrm{Sn}$ as a dopant in the $\mathrm{In}_{2} \mathrm{O}_{3} \mathrm{NC}$ lattice.
To check the efficiency of $\mathrm{Zr}^{4+}$ in reducing electron scattering from ionized impurities, we made Series-3, where a small amount of $\mathrm{Zr}(0.5-1.0 \%)$ was codoped with small $(\sim 1 \%)$, intermediate $(\sim 5 \%)$, and high $(\sim 8 \%)$ Sn doping percentages to form $\mathrm{Sn}, \mathrm{Zr}: \mathrm{In}_{2} \mathrm{O}_{3} \mathrm{NCs}$ and compared these with $\mathrm{Sn}: \mathrm{In}_{2} \mathrm{O}_{3} \mathrm{NCs}$ having roughly the same $\mathrm{Sn}$ doping percentage. Since $\mathrm{Zr}^{4+}$ is an aliovalent donor, doping in small amounts is expected to shift the LSPR energy, but if it contributes to ionized impurity scattering, it would also induce an increased linewidth (FWHM) of the LSPR band.

We observe that $\mathrm{Zr}$ codoping in $\mathrm{Sn}: \mathrm{In}_{2} \mathrm{O}_{3}$ NCs leads to an increase in the LSPR energy (as compared to $\mathrm{Sn}: \mathrm{In}_{2} \mathrm{O}_{3} \mathrm{NCs}$ with the same Sn doping percentage) for both low and intermediate $\mathrm{Sn}$ doping percentages, For high $\mathrm{Sn}$ doping concentration, however, codoping $\mathrm{Zr}$ with $\mathrm{Sn}$ leads to a decrease in the LSPR energy. $\mathrm{Zr}$ codoping in $\mathrm{Sn}: \mathrm{In}_{2} \mathrm{O}_{3}$ leads to a decrease in the size of the NCs (increase in surface to volume ratio), which places more $\mathrm{Sn}$ ions close to the surface than in the core, for a constant doping percentage. Since surface $\mathrm{Sn}$ dopants have been found to be less activated than the core $\mathrm{Sn}$ dopants, a decrease in NC diameter brings down the overall activation of $\mathrm{Sn}$ dopants leading to smaller LSPR energies. ${ }^{1622}$ $\mathrm{Zr}$ codoping in $\mathrm{Sn}: \mathrm{In}_{2} \mathrm{O}_{3} \mathrm{NCs}$ also decreases the LSPR FWHM and induces a highly symmetric line shape to the LSPR band. This observation, which is constant across all $\mathrm{Sn}, \mathrm{Zr}: \mathrm{In}_{2} \mathrm{O}_{3} \mathrm{NCs}$, is also reiterated by the LSPR parameters (Table ST1) where $\mathrm{Sn}, \mathrm{Zr}: \mathrm{In}_{2} \mathrm{O}_{3}$ NCs are found to display LSPR FWHMs approximately $20 \%$ smaller than their $\mathrm{Sn}_{2} \mathrm{In}_{2} \mathrm{O}_{3} \quad \mathrm{NCs}$ counterparts. Correspondingly, a $20 \%$ enhancement in the LSPR Q-factor is seen, despite a decrease in LSPR energy for the $1.0 \% \mathrm{Zr}-7.5 \% \mathrm{Sn}$ codoped $\mathrm{In}_{2} \mathrm{O}_{3}$ NCs. Since the degree of surface segregation of the $\mathrm{Sn}$ dopants is similar between $\mathrm{Sn}: \mathrm{In}_{2} \mathrm{O}_{3} \mathrm{NCs}$ and $\mathrm{Sn}, \mathrm{Zr}: \mathrm{In}_{2} \mathrm{O}_{3} \mathrm{NCs}$, we don't consider changes in dopant radial distribution as a potential contributor to the decrease in the LSPR FWHM (Figure S7 and S8). Therefore, $\mathrm{Zr}$ doping in $\mathrm{In}_{2} \mathrm{O}_{3}$ can be associated with high Q-factors and $1.0 \% \mathrm{Zr}-7.5 \%$ Sn codoped $\mathrm{In}_{2} \mathrm{O}_{3} \mathrm{NCs}$ exhibit an LSPR Q-factor of 5.3 (identical to $0.9 \% \mathrm{Zr}-1.9 \% \mathrm{Sn}$ ), among the highest in the literature (Table ST2). Hence, the three series give a conclusive evidence that $\mathrm{Zr}$ doping in $\mathrm{In}_{2} \mathrm{O}_{3} \mathrm{NCs}$ leads to a combination of high dopant activation, narrow LSPR linewidth, and high Qfactor. a

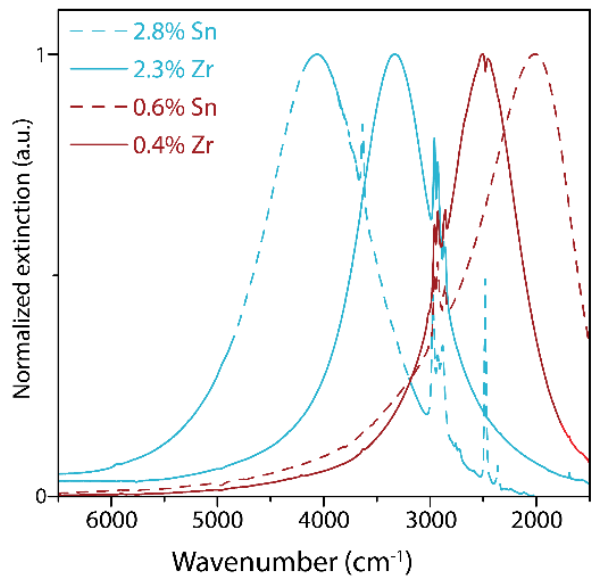

b

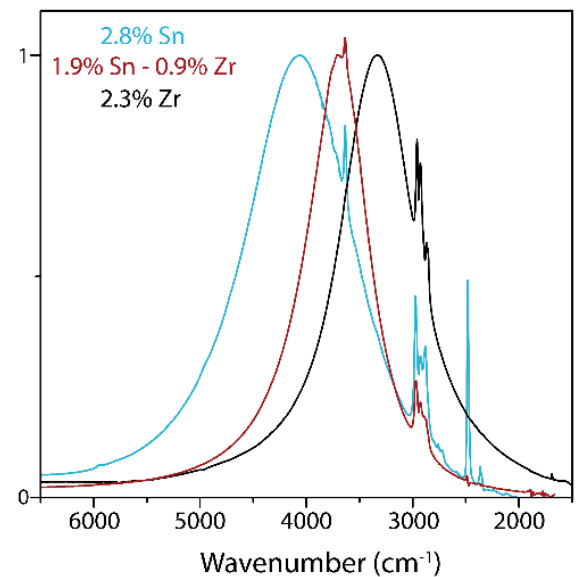

C

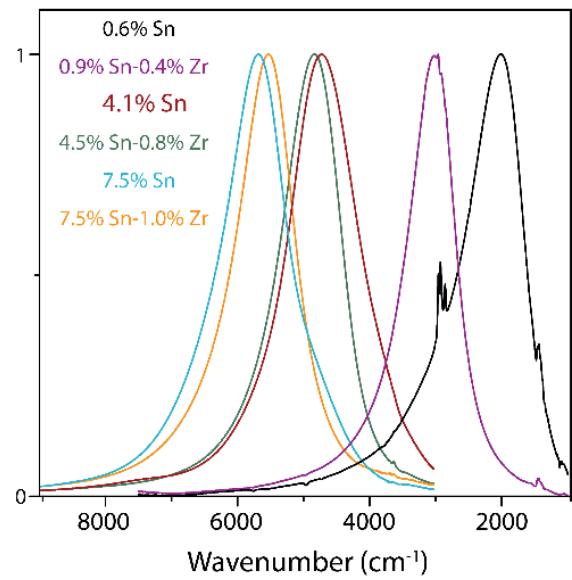

Figure 4: FTIR spectra of doped $\operatorname{In}_{2} \mathrm{O}_{3}$ NCs. Establishing the high dopant activation behavior but better aliovalent nature of $\mathrm{Zr}^{4+}$ ions over $\mathrm{Sn}^{4+}$ ions by comparing FTIR spectra in (i) Series-1, Zr: $\operatorname{In}_{2} \mathrm{O}_{3}$ and $\mathrm{Sn}: \mathrm{In}_{2} \mathrm{O}_{3}$ NCs with similar doping percentage (ii) $\mathrm{Series}-2$, $\mathrm{Zr}: \mathrm{In}_{2} \mathrm{O}_{3}$, $\mathrm{Sn}, \mathrm{Zr}: \mathrm{In}_{2} \mathrm{O}_{3}$ and $\mathrm{Sn}: \mathrm{In}_{2} \mathrm{O}_{3}$ NCs with similar total cation doping percentage (iii) Series-3, $\mathrm{Sn}, \mathrm{Zr}: \mathrm{In}_{2} \mathrm{O}_{3}$ and $\mathrm{Sn}_{\mathrm{In}} \mathrm{O}_{3} \mathrm{NCs}$ with similar $\mathrm{Sn}$ 


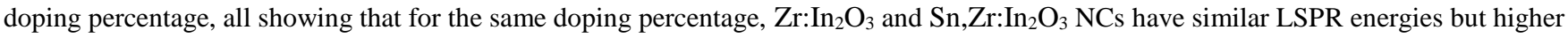
LSPR Q-factors as compared to $\mathrm{Sn}: \mathrm{In}_{2} \mathrm{O}_{3} \mathrm{NCs}$.

For a further quantitative interpretation, we modeled the LSPR response of all our NCs with the simple Drude and the extended Drude models by employing a MATLAB code. Since the optical properties of a material are governed by its complex dielectric function, both the carrier density and damping of charge carriers can be accounted for by considering the free carrier contribution to the complex dielectric function. ${ }^{16,27}$ For noble metals, this is given by the simple Drude model which can be represented as

$$
\varepsilon_{D}=\varepsilon_{\infty}-\frac{\omega_{p}^{2}}{\omega^{2}+i \omega \Gamma}
$$

where $\omega_{P}$ is the bulk plasma frequency defined in equation (2), $\varepsilon_{\infty}$ is the high-frequency dielectric constant, $\Gamma$ is the damping constant, and $\omega$ is the angular frequency of the incoming electromagnetic radiation. However, this simple Drude model does not take into account the contribution of ionized impurity scattering, which is a major scattering mechanism in doped semiconductors. For this purpose, in doped semiconductor systems, we often use the extended Drude model where the frequency-independent damping constant $\Gamma$ in the simple Drude is replaced by a frequency-dependent analogue $\Gamma(\omega)$ symbolized through the empirical equation ${ }^{16}$,

$$
\Gamma(\omega)=\Gamma_{L}-\frac{\Gamma_{L}-\Gamma_{H}}{\pi}\left[\tan ^{-1}\left(\frac{\omega-\Gamma_{X}}{\Gamma_{W}}\right)+\frac{\pi}{2}\right]
$$

where $\Gamma_{L}$ and $\Gamma_{H}$ are the low-frequency and high-frequency damping constants respectively, $\Gamma_{X}$ is the crossover-frequency from the low to high frequency region and $\Gamma_{W}$ is the width of the crossover region. The value of $\Gamma_{L}$ qualitatively signifies the extent of scattering by ionized dopants and therefore, to achieve a low LSPR FWHM and symmetric LSPR band, $\Gamma_{L}$ should be minimized. Since the extent of carrier scattering is determined by the damping constants, carrier mobilities can also be derived optically from the damping function using

$$
\mu_{\text {opt }}=\frac{e}{m^{*} \Gamma(0)}
$$

where we assume that the electrostatic potential at low frequencies would be equivalent to the carriers moving under the influence of a DC electric field and therefore, we employ $\Gamma(0)$, which is the value of the damping function at zero frequency. $^{21}$

Using the methodology described in section S3, we fitted the optical extinction spectra of all NCs with both the simple and the extended Drude models and extracted the values of bulk plasma frequency, electron density, damping constants, and the optical electron mobilities. Representative plots for both $\mathrm{Zr}: \mathrm{In}_{2} \mathrm{O}_{3}$ and $\mathrm{Sn}, \mathrm{Zr}: \mathrm{In}_{2} \mathrm{O}_{3} \mathrm{NCs}$ are shown in Figure $5 \mathrm{a}$ and $\mathrm{b}$, respectively, and fitting parameters are tabulated for simple Drude and extended Drude models in Table ST3 and ST4, respectively. The residual fits are presented in Figure S9. Excellent fits could be achieved for all the Zr-containing NCs, for both simple Drude and extended Drude model suggesting that only the free electron density is responsible for the optical absorption.

Discussing the fit parameters for the extended Drude model first, almost all $\mathrm{Zr}: \operatorname{In}_{2} \mathrm{O}_{3}$ and $\mathrm{Sn}, \mathrm{Zr}: \mathrm{In}_{2} \mathrm{O}_{3} \mathrm{NCs}$ have a small $\Gamma_{L}$ (and $\Gamma_{L} \ll \Gamma_{H}$ ), crossover frequency $\Gamma_{x}$ at energies much higher than the LSPR peak position, and narrow crossover width $\left(\Gamma_{w}\right)$. These observations are strong indications that there is minimized impurity scattering in both $\mathrm{Zr}: \mathrm{In}_{2} \mathrm{O}_{3}$ and $\mathrm{Sn}, \mathrm{Zr}: \mathrm{In}_{2} \mathrm{O}_{3}$ $\mathrm{NCs}$ and electron scattering in these NCs is largely frequencyindependent. In contrast, $\mathrm{Sn}: \mathrm{In}_{2} \mathrm{O}_{3} \mathrm{NCs}$ with similar doping concentration are found to have a $\Gamma_{L} \gg \Gamma_{H}$, small crossover frequencies and large crossover widths. This indicates that ionized impurity scattering is still prominent in these NCs, which contributes to broadened LSPR linewidths. Regardless of this, both $4.1 \%$ and $7.5 \% \mathrm{Sn}: \mathrm{In}_{2} \mathrm{O}_{3} \mathrm{NCs}$ display appreciably high LSPR Q-factors, which can be attributed in part to the observed slight surface segregation of $\mathrm{Sn}$ at high doping percentages that has been found to decrease the electrostatic interactions between the electrons and the ionized dopants and also to their large size, which decreases surface scattering. However, the overall trend that $\mathrm{Zr}: \mathrm{In}_{2} \mathrm{O}_{3}$ and $\mathrm{Sn}, \mathrm{Zr}: \mathrm{In}_{2} \mathrm{O}_{3} \mathrm{NCs}$ exhibit much smaller $\Gamma_{L}$ than $\mathrm{Sn}: \mathrm{In}_{2} \mathrm{O}_{3} \mathrm{NCs}$ (which leads to high LSPR Q-factors) with the same doping percentage, is robust, as evident by Figure 5c. The smallest $\Gamma_{L}$ is exhibited by undoped $\mathrm{In}_{2} \mathrm{O}_{3} \mathrm{NCs}$, which is understandable because electrons therein are only scattered by the oxygen vacancies unlike doped $\operatorname{In}_{2} \mathrm{O}_{3}$ NCs where aliovalent dopants act as majority scattering centers with additional contribution from oxygen vacancies. Furthermore, comparing the electron density obtained from the extended Drude (Table ST3) fittings reveals that Sn and Zr have similar electron density for the same doping percentage, which is in agreement with our initial hypothesis and the results obtained from Series 1-3. A direct consequence of the low $\Gamma_{L}$ is reflected in the high mobility values obtained for $\mathrm{Sn}, \mathrm{Zr}: \mathrm{In}_{2} \mathrm{O}_{3}$ and $\mathrm{Zr}: \operatorname{In}_{2} \mathrm{O}_{3}$ NCs (Table ST3). However, since electron scattering in our NCs seems to be operating through a frequency-independent mechanism, we will instead use parameters derived by fitting to the simple Drude model, which has fewer fit parameters and minimizes uncertainty, to draw additional conclusions about the electronic properties. Moreover, the optical spectra of some NCs have a contribution from the $\mathrm{C}-\mathrm{H}$ vibrational stretch absorption of the ligands around $3000 \mathrm{~cm}^{-1}$, which complicates quantitative fitting of the LSPR; this overlapping signal can lead to unreasonably large variations in the value of the parameters in some cases, which is less of a challenge if the fit is constrained with fewer free parameters. 

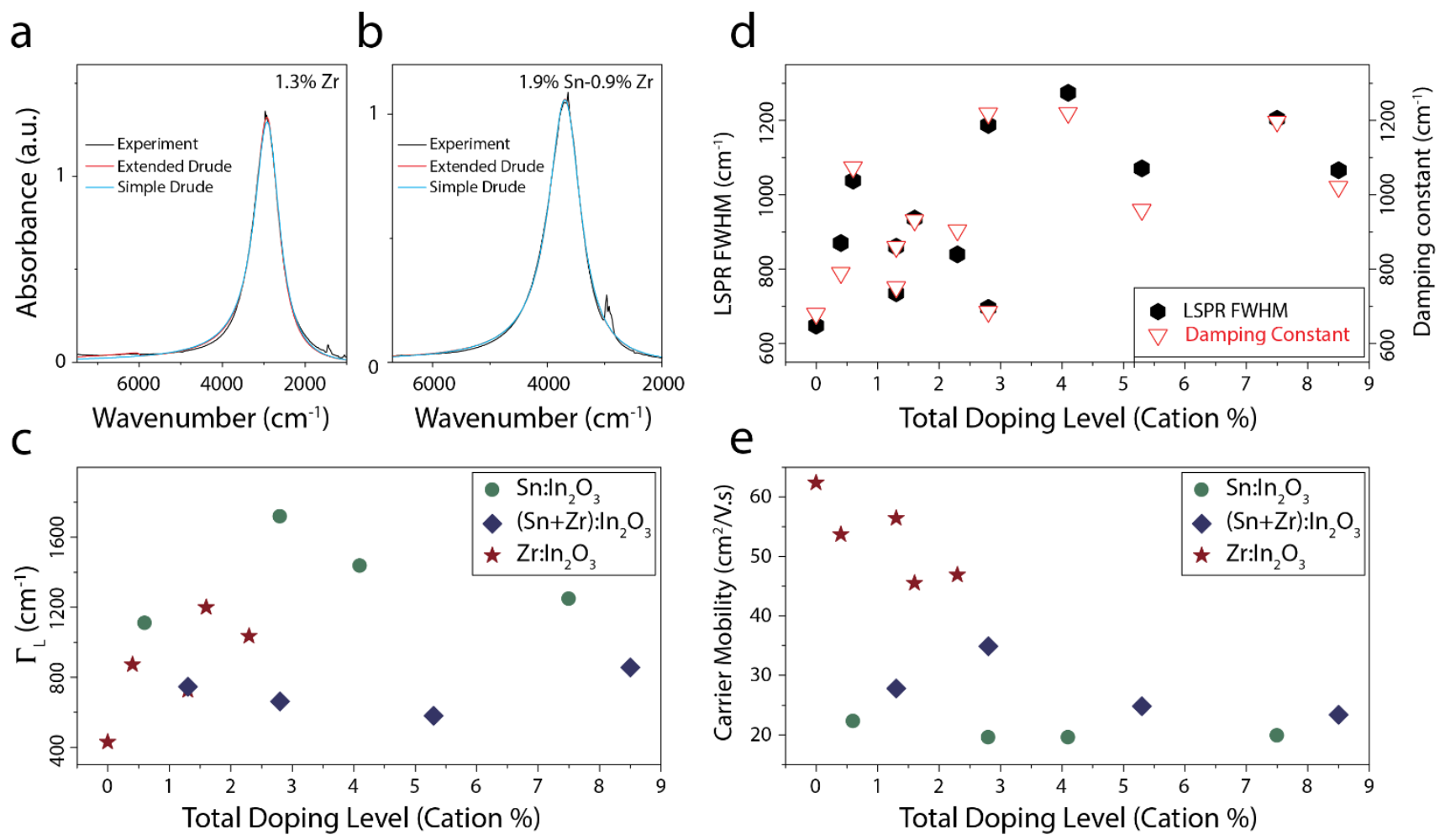

Figure 5: Fitting of the optical spectra using the simple and extended Drude models. (a,b) Representative Drude model fits to the LSPR spectra of $1.3 \% \mathrm{Zr}$-doped and $0.9 \% \mathrm{Sn}-0.4 \%$ Sn codoped $\mathrm{In}_{2} \mathrm{O}_{3} \mathrm{NCs}$ showing excellent fitting. (c) Comparison of the low frequency damping constants obtained from extended Drude model fits for different NCs indicating much smaller values of $\Gamma_{L}$ and hence low electron scattering for $\mathrm{Zr}: \mathrm{In}_{2} \mathrm{O}_{3}$ and $\mathrm{Sn}, \mathrm{Zr}: \mathrm{In}_{2} \mathrm{O}_{3} \mathrm{NCs}$ than $\mathrm{Sn}: \mathrm{In}_{2} \mathrm{O}_{3}$ NCs. (d) Correlation between damping constant obtained from simple Drude model fits and experimental LSPR FWHM signifying frequency independence of electron scattering in almost all NCs. (e) Comparison of optical electron mobilities obtained from the simple Drude model shows 3 times enhancement by changing the dopant from $\mathrm{Sn}^{4+}$ to $\mathrm{Zr}^{4+}$ due to reduced electron scattering.

Nonetheless, as described before, excellent fits could be achieved by modeling the absorption spectra through the simple Drude model signifying that electron scattering mechanism in $\mathrm{Zr}: \mathrm{In}_{2} \mathrm{O}_{3}$ and $\mathrm{Sn}, \mathrm{Zr}: \operatorname{In}_{2} \mathrm{O}_{3}$ NCs, is largely frequency independent, similar to that of noble metal NCs. The estimated values of bulk plasma frequency and electron density (Table ST4) are roughly equivalent to those determined from the extended Drude model. From Table ST4, one can observe that the damping constants for both $\mathrm{Zr}: \mathrm{In}_{2} \mathrm{O}_{3}$ and $\mathrm{Sn}, \mathrm{Zr}: \mathrm{In}_{2} \mathrm{O}_{3} \mathrm{NCs}$ are very close to that of the undoped $\mathrm{In}_{2} \mathrm{O}_{3} \quad \mathrm{NCs}$ and significantly smaller than those of the $\mathrm{Sn}: \mathrm{In}_{2} \mathrm{O}_{3} \mathrm{NCs}$, which reiterates our claims of minimized ionized impurity scattering in $\mathrm{Zr}: \mathrm{In}_{2} \mathrm{O}_{3}$ and $\mathrm{Sn}, \mathrm{Zr}: \mathrm{In}_{2} \mathrm{O}_{3}$ NCs. A perfect correlation was observed between the damping constants and the experimental LSPR FWHM for almost all the NCs, as shown in Figure 5d. This signifies that the simple Drude model is a good representation of the LSPR and frequency dependent damping is not needed to describe the dominant electron scattering processes in our NCs, especially $\mathrm{Zr}: \mathrm{In}_{2} \mathrm{O}_{3}$ and $\mathrm{Sn}, \mathrm{Zr}: \mathrm{In}_{2} \mathrm{O}_{3} \mathrm{NCs}$. Using the single damping constant in equation (5), we determined the electron mobilities of different NCs and plotted them in Figure 5e. The electron mobilities of $\mathrm{Zr}: \mathrm{In}_{2} \mathrm{O}_{3} \mathrm{NCs}$ are almost 3 times greater than that of $\mathrm{Sn}: \mathrm{In}_{2} \mathrm{O}_{3}$ NCs and lie very close to that of the undoped $\mathrm{In}_{2} \mathrm{O}_{3}$ NCs. Even the $\mathrm{Sn}, \mathrm{Zr}: \mathrm{In}_{2} \mathrm{O}_{3}$ NCs exhibit electron mobilities $30-80 \%$ greater than $\mathrm{Sn}: \mathrm{In}_{2} \mathrm{O}_{3}$ $\mathrm{NCs}$ and close to those reported for Ce-doped $\mathrm{In}_{2} \mathrm{O}_{3} \mathrm{NCs}$. For the electron mobility calculations, the effective carrier mass for $\mathrm{Sn}: \mathrm{In}_{2} \mathrm{O}_{3}$ and $\mathrm{Sn}, \mathrm{Zr}: \mathrm{In}_{2} \mathrm{O}_{3} \mathrm{NCs}$ was approximated as $0.39 \mathrm{~m}_{\mathrm{e}}$ whereas that for $\mathrm{Zr}: \mathrm{In}_{2} \mathrm{O}_{3} \mathrm{NCs}$ was $0.22 \mathrm{~m}_{\mathrm{e}}$ as suggested by Xu et al. ${ }^{28}$ Even if the same effective carrier mass is assumed, the electron mobilities in $\mathrm{Zr}: \operatorname{In}_{2} \mathrm{O}_{3} \mathrm{NCs}$ would be equivalent if not greater to that of Ce-doped $\mathrm{In}_{2} \mathrm{O}_{3} \mathrm{NCs} .{ }^{26}$ We attribute this extraordinary electronic quality of $\mathrm{Zr}: \mathrm{In}_{2} \mathrm{O}_{3} \mathrm{NCs}$ to the optimized position of the $\mathrm{Zr}$ defect level in the electronic band structure of $\operatorname{In}_{2} \mathrm{O}_{3}$ coupled with surface segregated $\mathrm{Zr}$ doping, which ensures that the electrostatic potentials experienced by the electrons do not change significantly through the lattice of $\mathrm{In}_{2} \mathrm{O}_{3}$. These effects combine to produce a rare combination of high LSPR Q-factor, high dopant activation, and low levels of electron scattering implying high electron mobilities, all in one material.

In conclusion, we describe the salient properties of an aliovalent dopant that determines its merit in generating high LSPR Q-factor in doped metal oxide NCs. For high LSPR energy, a donor state deep in the conduction band of the host and a stable oxidation state is required, whereas a small LSPR FWHM demands a higher charge to radius ratio and lower electronegativity of the dopant cation with respect to the host cation. Using these selection criteria, we propose $\mathrm{Zr}^{4+}$ as an ideal aliovalent dopant in the $\operatorname{In}_{2} \mathrm{O}_{3}$ lattice and report the synthesis of $\mathrm{Zr}$-doped $\mathrm{In}_{2} \mathrm{O}_{3} \mathrm{NCs}$ for the first time. The resulting $\mathrm{Zr}: \mathrm{In}_{2} \mathrm{O}_{3} \mathrm{NCs}$ exhibit a rare combination of high dopant activation and low LSPR FWHM, leading to one of the highest $\mathrm{Q}$-factors in the literature on plasmonic nanomaterials. We further prove that our $\mathrm{Zr}: \operatorname{In}_{2} \mathrm{O}_{3} \mathrm{NCs}$ are comparable to the best materials for dopant activation (Sn-doped $\operatorname{In}_{2} \mathrm{O}_{3} \mathrm{NCs}$ ) and LSPR FWHM (Ce-doped $\mathrm{In}_{2} \mathrm{O}_{3} \mathrm{NCs}$ ), simultaneously. Drude fittings of the optical spectra reveal that the electron mobilities in our $\mathrm{Zr}: \operatorname{In}_{2} \mathrm{O}_{3}$ NCs are 3 times as that of $\mathrm{Sn}: \operatorname{In}_{2} \mathrm{O}_{3} \mathrm{NCs}$ and equivalent to undoped $\mathrm{In}_{2} \mathrm{O}_{3} \mathrm{NCs}$, indicating that ionized 
impurity scattering is essentially absent in our $\mathrm{Zr}: \operatorname{In}_{2} \mathrm{O}_{3} \mathrm{NCs}$. We conclude that the optimized placement of $\mathrm{Zr}$ donor levels in the conduction band of $\operatorname{In}_{2} \mathrm{O}_{3}$ and surface segregated doping of $\mathrm{Zr}$ are responsible for the enhanced electron mobilities and could very much enable $\mathrm{Zr}: \mathrm{In}_{2} \mathrm{O}_{3} \mathrm{NCs}$ and films based on these as benchmark materials for applications such as transparent conducting electrodes to be used in flat panel displays and thin film photovoltaics. Since a high Q-factor also facilitates enhanced plasmonic hot spot generation and near-field enhancement, we are confident that $\mathrm{Zr}: \mathrm{In}_{2} \mathrm{O}_{3} \mathrm{NCs}$ would be an excellent system for applications like SEIRA and plasmonic sensing. Advancements in the colloidal synthesis of $\mathrm{Zr}: \operatorname{In}_{2} \mathrm{O}_{3}$ NCs will permit to achieve higher levels of $\mathrm{Zr}$ incorporation in the $\operatorname{In}_{2} \mathrm{O}_{3}$ lattice and one would, therefore, be able to achieve high LSPR Q-factor through the entire near to mid-infrared range. The approach for this rational dopant selection can ideally be applied to any other metal oxide system like $\mathrm{TiO}_{2}$, $\mathrm{ZnO}, \mathrm{SnO}_{2}$ and additional research in this direction could allow realization of advantageous properties from a broad range of host compositions. A first glimpse of the extendibility of this strategy this can be seen in Figure $\mathrm{S} 10$ where $\mathrm{Hf}^{4+}$ doping in $\mathrm{In}_{2} \mathrm{O}_{3}$ (the chemical properties of $\mathrm{Hf}$ are very similar to $\mathrm{Zr}$ due to lanthanide contraction) also leads to a narrow LSPR in the mid-infrared range.

\section{Associated content}

The Supporting Information is available.

Details of nanocrystal characterization (STEM, XPS, XRD) and Drude modeling scheme along with the fits to the optical extinction spectra and parameters obtained.

\section{Author information}

Corresponding author e-mail: milliron@che.utexas.edu

\section{Acknowledgements}

B. Tandon, S. Ghosh, and D. J. Milliron acknowledge support from the National Science Foundation (NSF, CHE-1609656), the Alfred P. Sloan Foundation (FG-2016-6446), CBMM, an NSF MRSEC (DMR-1720595), the Welch Foundation (F1848), and the Fulbright-Nehru Doctoral Research Programme. We also thank Ms. Camila Saez Cabezas of UT Austin for help with Raman measurements and Mr. Deepak Khurana of IISERPune for assistance with Drude modeling.

\section{References}

(1) Minami, T., New n-Type Transparent Conducting Oxides. MRS Bull. 2011, 25, 38-44.

(2) Agrawal, A.; Cho, S. H.; Zandi, O.; Ghosh, S.; Johns, R. W.; Milliron, D. J., Localized Surface Plasmon Resonance in Semiconductor Nanocrystals. Chem. Rev. 2018, 118, 3121-3207.

(3) Willets, K. A.; Duyne, R. P. V., Localized Surface Plasmon Resonance Spectroscopy and Sensing. Annu. Rev. Phys. Chem. 2007, 58, 267-297.

(4) Faucheaux, J. A.; Stanton, A. L. D.; Jain, P. K., Plasmon Resonances of Semiconductor Nanocrystals: Physical Principles and New Opportunities. J. Phys. Chem. Lett. 2014, 5, 976-985.

(5) Liu, X.; Swihart, M. T., Heavily-Doped Colloidal Semiconductor and Metal Oxide Nanocrystals: An Emerging New Class of Plasmonic Nanomaterials. Chem. Soc. Rev. 2014, 43, 3908-3920.

(6) Tandon, B.; Ashok, A.; Nag, A., Colloidal Transparent Conducting Oxide Nanocrystals: A New Infrared Plasmonic Material. Pramana 2015, 84, 1087-1098.

(7) Agrawal, A.; Johns, R. W.; Milliron, D. J., Control of Localized Surface Plasmon Resonances in Metal Oxide Nanocrystals. Annu. Rev. Mater. Res. 2017, 47, 1-31.

(8) Haes, A. J.; Hall, W. P.; Chang, L.; Klein, W. L.; Van Duyne, R. P., A Localized Surface Plasmon Resonance Biosensor: First Steps toward an Assay for Alzheimer's Disease. Nano Lett. 2004, 4, 1029-1034.
(9) Sannomiya, T.; Hafner, C.; Voros, J., In situ Sensing of Single Binding Events by Localized Surface Plasmon Resonance. Nano Lett. 2008, 8, 34503455.

(10) Verellen, N.; Van Dorpe, P.; Huang, C.; Lodewijks, K.; Vandenbosch, G. A. E.; Lagae, L.; Moshchalkov, V. V., Plasmon Line Shaping Using Nanocrosses for High Sensitivity Localized Surface Plasmon Resonance Sensing. Nano Lett. 2011, 11, 391-397.

(11) Jain, P. K.; Huang, X.; El-Sayed, I. H.; El-Sayed, M. A., Noble Metals on the Nanoscale: Optical and Photothermal Properties and Some Applications in Imaging, Sensing, Biology, and Medicine. Acc. Chem. Res. 2008, 41, 1578-1586.

(12) Atwater, H. A.; Polman, A., Plasmonics for Improved Photovoltaic Devices. Nat. Mater. 2010, 9, 205-213.

(13) Garcia, G.; Buonsanti, R.; Llordes, A.; Runnerstrom, E. L.; Bergerud, A.; Milliron, D. J., Near-Infrared Spectrally Selective Plasmonic Electrochromic Thin Films. Adv. Opt. Mater. 2013, 1, 215-220.

(14) Garcia, G.; Buonsanti, R.; Runnerstrom, E. L.; Mendelsberg, R. J.; Llordes, A.; Anders, A.; Richardson, T. J.; Milliron, D. J., Dynamically Modulating the Surface Plasmon Resonance of Doped Semiconductor Nanocrystals. Nano Lett. 2011, 11, 4415-4420.

(15) Wang, Y.; Runnerstrom, E. L.; Milliron, D. J., Switchable Materials for Smart Windows. Annu. Rev. Chem. Biomol. Eng. 2016, 7, 283-304.

(16) Lounis, S. D.; Runnerstrom, E. L.; Llordés, A.; Milliron, D. J., Defect Chemistry and Plasmon Physics of Colloidal Metal Oxide Nanocrystals. $J$. Phys. Chem. Lett. 2014, 5, 1564-1574.

(17) Rueben, J. M.; Yuankun, Z.; André, A., Determining the Nonparabolicity Factor of the $\mathrm{CdO}$ Conduction Band using Indium Doping and the Drude Theory. J. Phys. D: Appl. Phys. 2012, 45, 425302.

(18) Gordon, T. R.; Paik, T.; Klein, D. R.; Naik, G. V.; Caglayan, H.; Boltasseva, A.; Murray, C. B., Shape-Dependent Plasmonic Response and Directed Self-Assembly in a New Semiconductor Building Block, IndiumDoped Cadmium Oxide (ICO). Nano Lett. 2013, 13, 2857-2863.

(19) Ye, X.; Fei, J.; Diroll, B. T.; Paik, T.; Murray, C. B., Expanding the Spectral Tunability of Plasmonic Resonances in Doped Metal-Oxide Nanocrystals through Cooperative Cation-Anion Codoping. J. Am. Chem. Soc. 2014, 136, 11680-11686.

(20) Kanehara, M.; Koike, H.; Yoshinaga, T.; Teranishi, T., Indium Tin Oxide Nanoparticles with Compositionally Tunable Surface Plasmon Resonance Frequencies in the Near-IR Region. J. Am. Chem. Soc. 2009, 131, 17736-17737.

(21) Lounis, S. D.; Runnerstrom, E. L.; Bergerud, A.; Nordlund, D.; Milliron, D. J., Influence of Dopant Distribution on the Plasmonic Properties of Indium Tin Oxide Nanocrystals. J. Am. Chem. Soc. 2014, 136, $7110-7116$.

(22) Tandon, B.; Yadav, A.; Khurana, D.; Reddy, P.; Santra, P. K.; Nag, A., Size-Induced Enhancement of Carrier Density, LSPR Quality Factor, and Carrier Mobility in Cr-Sn Doped $\mathrm{In}_{2} \mathrm{O}_{3}$ Nanocrystals. Chem. Mater. 2017, 29, 9360-9368.

(23) Hamberg, I.; Granqvist, C. G., Optical Properties of Transparent and Heat-Reflecting Indium Tin Oxide Films: The role of ionized impurity scattering. Appl. Phys. Lett. 1984, 44, 721-723.

(24) Hamberg, I.; Granqvist, C. G., Evaporated Sn-doped $\operatorname{In}_{2} \mathrm{O}_{3}$ films: Basic Optical Properties and Applications to Energy-Efficient Windows. J. Appl. Phys. 1986, 60, R123-R160.

(25) Zhang, D. H.; Ma, H. L., Scattering Mechanisms of Charge Carriers in Transparent Conducting Oxide Films. Appl. Phys. A 1996, 62, 487-492.

(26) Runnerstrom, E. L.; Bergerud, A.; Agrawal, A.; Johns, R. W.; Dahlman, C. J.; Singh, A.; Selbach, S. M.; Milliron, D. J., Defect Engineering in Plasmonic Metal Oxide Nanocrystals. Nano Lett. 2016, 16, 3390-3398.

(27) Mendelsberg, R. J.; Garcia, G.; Li, H.; Manna, L.; Milliron, D. J., Understanding the Plasmon Resonance in Ensembles of Degenerately Doped Semiconductor Nanocrystals. J. Phys. Chem. C 2012, 116, 1222612231.

(28) Xu, J.; Liu, J. B.; Liu, B. X.; Li, S. N.; Wei, S. H.; Huang, B., Design of n-Type Transparent Conducting Oxides: The Case of Transition Metal Doping in $\operatorname{In}_{2} \mathrm{O}_{3}$. Adv. Electron. Mater. 2018, 4, 1700553.

(29) Bhachu, D. S.; Scanlon, D. O.; Sankar, G.; Veal, T. D.; Egdell, R. G.; Cibin, G.; Dent, A. J.; Knapp, C. E.; Carmalt, C. J.; Parkin, I. P., Origin of High Mobility in Molybdenum-Doped Indium Oxide. Chem. Mater. 2015, 27, 2788-2796.

(30) Tandon, B.; Shanker, G. S.; Nag, A., Multifunctional Sn- and FeCodoped $\mathrm{In}_{2} \mathrm{O}_{3}$ Colloidal Nanocrystals: Plasmonics and Magnetism. $J$. Phys. Chem. Lett. 2014, 5, 2306-2311. 
(31) Tandon, B.; Yadav, A.; Nag, A., Delocalized Electrons Mediated Magnetic Coupling in $\mathrm{Mn}-\mathrm{Sn}$ Codoped $\mathrm{In}_{2} \mathrm{O}_{3}$ Nanocrystals: Plasmonics Shows the Way. Chem. Mater. 2016.

(32) Yadav, A.; Tandon, B.; Nag, A., Reduction of $\mathrm{Mn}^{3+}$ to $\mathrm{Mn}^{2+}$ and near infrared plasmonics from $\mathrm{Mn}-\mathrm{Sn}$ codoped $\mathrm{In}_{2} \mathrm{O}_{3}$ nanocrystals. $R S C A d v$. 2016, 6, 79153-79159.

(33) Shanker, G. S.; Tandon, B.; Shibata, T.; Chattopadhyay, S.; Nag, A., Doping Controls Plasmonics, Electrical Conductivity, and CarrierMediated Magnetic Coupling in $\mathrm{Fe}$ and $\mathrm{Sn}$ Codoped $\mathrm{In}_{2} \mathrm{O}_{3}$ Nanocrystals: Local Structure Is the Key. Chem. Mater. 2015, 27, 892-900.

(34) Frank, G.; Köstlin, H., Electrical Properties and Defect Model of Tindoped Indium Oxide Layers. Appl. Phys. A 1982, 27, 197-206.

(35) Warschkow, O.; Ellis, D. E.; González, G. B.; Mason, T. O., Defect Cluster Aggregation and Nonreducibility in Tin-Doped Indium Oxide. $J$. Am. Ceram. Soc. 2003, 86, 1707-1711.

(36) González, G. B.; Mason, T. O.; Quintana, J. P.; Warschkow, O.; Ellis, D. E.; Hwang, J.-H.; Hodges, J. P.; Jorgensen, J. D., Defect Structure Studies of Bulk and Nano-Indium-Tin Oxide. J. Appl. Phys. 2004, 96, 39123920 .

(37) Staller, C. M.; Agrawal, A.; Gibbs, S. L.; Saez Cabezas, C. A.; Johns, R. W.; Milliron, D. J. Quantitative Analysis of Semiconductor Nanocrystal Ensemble Optical Extinction arXiv e-prints [Online], 2018 https://ui.adsabs.harvard.edu/abs/2018arXiv181210142S (accessed December 01, 2018).

(38) Zhang, Y., Electronegativities of Elements in Valence States and their Applications. 2. A Scale for Strengths of Lewis acids. Inorg. Chem. 1982, 21, 3889-3893.

(39) Zhang, Y., Electronegativities of Elements in Valence States and their Applications. 1. Electronegativities of Elements in Valence States. Inorg. Chem. 1982, 21, 3886-3889.

(40) Shannon, R. D.; Prewitt, C. T., Effective Ionic Radii in Oxides and Fluorides. Acta Crystallogr. Sect. B 1969, 25, 925-946.

(41) Koida, T.; Kondo, M., High-Mobility Transparent Conductive Zrdoped $\mathrm{In}_{2} \mathrm{O}_{3}$. Appl. Phys. Lett. 2006, 89, 082104.

(42) Koida, T.; Kondo, M., Improved Near-Infrared Transparency in Sputtered $\mathrm{In}_{2} \mathrm{O}_{3}$-based Transparent Conductive Oxide Thin Films by $\mathrm{Zr}$ doping. J. Appl. Phys. 2007, 101, 063705.

(43) Guilmeau, E.; Bérardan, D.; Simon, C.; Maignan, A.; Raveau, B.; Ovono, D. O.; Delorme, F., Tuning the Transport and Thermoelectric Properties of $\mathrm{In}_{2} \mathrm{O}_{3}$ Bulk Ceramics through Doping at In-site. J. Appl. Phys. 2009, 106, 053715 .
(44) Jansons, A. W.; Hutchison, J. E., Continuous Growth of Metal Oxide Nanocrystals: Enhanced Control of Nanocrystal Size and Radial Dopant Distribution. ACS Nano 2016, 10, 6942-6951.

(45) Narayanaswamy, A.; Xu, H.; Pradhan, N.; Kim, M.; Peng, X., Formation of Nearly Monodisperse $\mathrm{In}_{2} \mathrm{O}_{3}$ Nanodots and Oriented-Attached Nanoflowers: Hydrolysis and Alcoholysis vs Pyrolysis. J. Am. Chem. Soc. 2006, 128, 10310-10319.

(46) Vegard, L., Die Konstitution der Mischkristalle und die Raumfüllung der Atome. Zeitschrift für Physik 1921, 5, 17-26.

(47) Nadaud, N.; Lequeux, N.; Nanot, M.; Jové, J.; Roisnel, T., Structural Studies of Tin-Doped Indium Oxide (ITO) and $\mathrm{In}_{4} \mathrm{Sn}_{3} \mathrm{O}_{12}$. J. Solid State Chem. 1998, 135, 140-148.

(48) Brewer, S. H.; Franzen, S., Calculation of the Electronic and Optical Properties of Indium Tin Oxide by Density Functional Theory. Chem. Phys. 2004, 300, 285-293.

(49) Jayakumar, O. D.; Gopalakrishnan, I. K.; Kulshreshtha, S. K.; Gupta, A.; Rao, K. V.; Louzguine-Luzgin, D. V.; Inoue, A.; Glans, P. A.; Guo, J. H.; Samanta, K.; Singh, M. K.; Katiyar, R. S., Structural and Magnetic Properties of $\left(\mathrm{In}_{1-\mathrm{x}} \mathrm{Fe}_{\mathrm{x}}\right)_{2} \mathrm{O}_{3} \quad(0.0 \leqslant \mathrm{x} \leqslant 0.25)$ System: Prepared by Gel Combustion Method. Appl. Phys. Lett. 2007, 91, 052504.

(50) Farvid, S. S.; Hegde, M.; Radovanovic, P. V., Influence of the Host Lattice Electronic Structure on Dilute Magnetic Interactions in Polymorphic $\mathrm{Cr}$ (III)-Doped $\mathrm{In}_{2} \mathrm{O}_{3}$ Nanocrystals. Chem. Mater. 2013, 25, 233-244.

(51) Wagner, C. D.; Muilenberg, G. E., Handbook of X-ray Photoelectron Spectroscopy : A Reference Book of Standard Data for Use in X-ray Photoelectron Spectroscopy. Physical Electronics Division, Perkin-Elmer Corp.: Eden Prairie, Minn., 1979.

(52) Dementjev, A. P.; Ivanova, O. P.; Vasilyev, L. A.; Naumkin, A. V.; Nemirovsky, D. M.; Shalaev, D. Y., Altered layer as Sensitive Initial Chemical State Indicator*. J. Vac. Sci. Technol., A 1994, 12, 423-427.

(53) Buonsanti, R.; Milliron, D. J., Chemistry of Doped Colloidal Nanocrystals. Chem. Mater. 2013, 25, 1305-1317.

(54) Crockett, B. M.; Jansons, A. W.; Koskela, K. M.; Johnson, D. W.; Hutchison, J. E., Radial Dopant Placement for Tuning Plasmonic Properties in Metal Oxide Nanocrystals. ACS Nano 2017, 11, 7719-7728.

(55) Erwin, S. C.; Zu, L.; Haftel, M. I.; Efros, A. L.; Kennedy, T. A.; Norris, D. J., Doping Semiconductor Nanocrystals. Nature 2005, 436, 91-94. 


\title{
Dopant Selection Strategy for High Quality Factor Localized Surface Plasmon Resonance from Doped Metal Oxide Nanocrystals
}

\author{
Bharat Tandon $^{\dagger \dagger}$, Sandeep Ghosh ${ }^{\dagger}$, Delia J. Milliron ${ }^{\dagger *}$ \\ ${ }^{\dagger}$ McKetta Department of Chemical Engineering, University of Texas at Austin, Austin, Texas 78712- \\ 1589, United States \\ ${ }^{\ddagger}$ Department of Chemistry, Indian Institute of Science Education and Research, Dr. Homi Bhabha Road, \\ Pune-411008, India
}

Supporting Information 


\section{Contents}

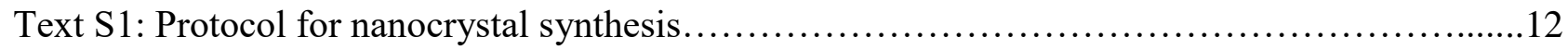

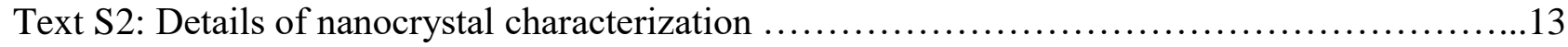

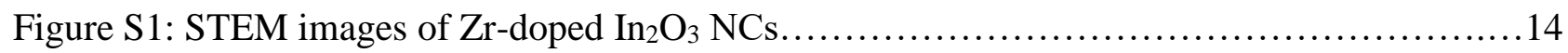

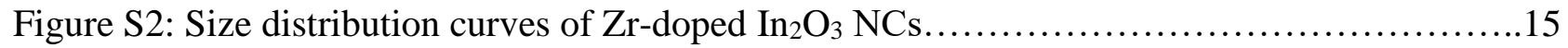

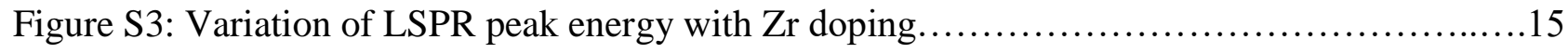

Table ST1: LSPR parameters of Zr-doped, Sn-doped and $\mathrm{Sn}, \mathrm{Zr}$ codoped $\mathrm{In}_{2} \mathrm{O}_{3} \mathrm{NCs} \ldots \ldots \ldots \ldots \ldots \ldots$

Table ST2: Comparison of LSPR parameters obtained with best LSPR materials in literature.......17

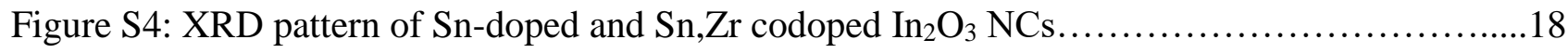

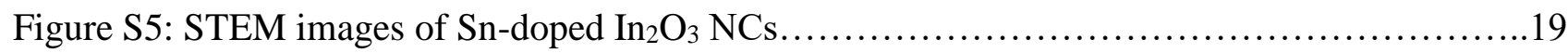

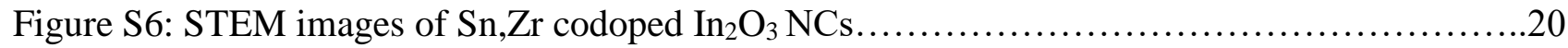

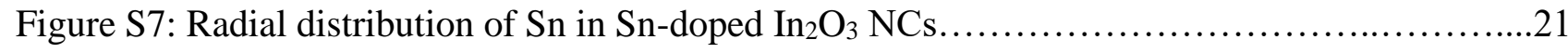

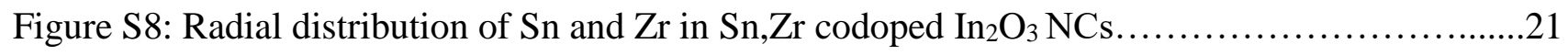

Text S3: Modeling scheme for simple and extended Drude model..............................21

Table ST3: Parameters obtained from extended Drude model fit .............................24

Table ST4: Parameters obtained from simple Drude model fit................................25

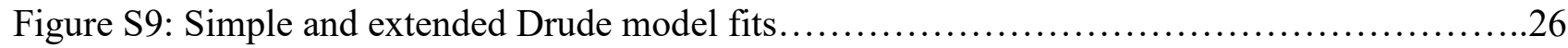

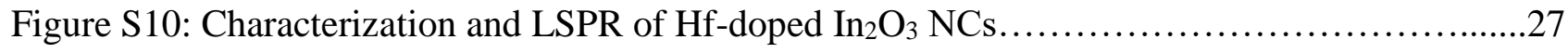

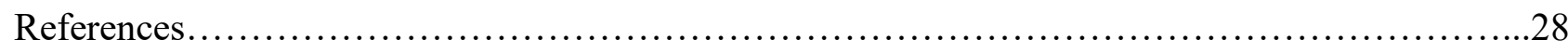




\section{Text S1: Nanocrystal Synthesis}

Chemicals: All chemicals used in the synthesis and characterization of nanocrystals were acquired commercially and no further purification step was carried out prior to their use. Indium(III) acetate (STREM, $\geq 99.99 \%$ ) zirconium(IV) acetylacetonate (Sigma-Aldrich, 97\%), tin(IV) acetate (SigmaAldrich 99.99\%), oleyl alcohol (Sigma-Aldrich, 85\%) and oleic acid (Sigma-Aldrich, 90\%) were used for the synthesis. Oleylamine (Sigma-Aldrich, 70\%), ethanol (Fischer Chemical, 90\%), hexane (Fischer Chemical $\geq 99.9 \%$ ) and tetrachloroethylene (Sigma-Aldrich, $\geq 99.9 \%$ ) were utilized for washing the resulting nanocrystals and characterizing them through different techniques.

\section{Synthesis Procedure:}

Different $\mathrm{Zr}$-doped, Sn-doped, and $\mathrm{Sn}-\mathrm{Zr}$ codoped $\mathrm{In}_{2} \mathrm{O}_{3} \mathrm{NCs}$ were synthesized by minor modifications of the slow-injection synthetic procedure developed by the Hutchison group. ${ }^{1}$ Using standard Schlenk line techniques, a $0.5 \mathrm{M}$ mixture of $\mathrm{In}$ and $\mathrm{Zr}$ precursors in $10 \mathrm{~mL}$ oleic acid was degassed at $100{ }^{\circ} \mathrm{C}$ under vacuum conditions, which was followed by an undisturbed heating and vigorous stirring at $150{ }^{\circ} \mathrm{C}$ under $\mathrm{N}_{2}$ atmosphere for 2 hours. $8 \mathrm{~mL}$ of this mixture was subsequently injected into an already degassed 13 $\mathrm{mL}$ solution of oleyl alcohol kept at $290^{\circ} \mathrm{C}$ (under $\mathrm{N}_{2}$ conditions) at the rate of $0.2 \mathrm{~mL} / \mathrm{min}$ using a syringe pump. Nanocrystals were separated from the reaction mixture impurities by repeatedly precipitating with ethanol, centrifugation at $9000 \mathrm{rpm}$ for $5 \mathrm{~min}$, and re-dispersing in hexane before finally being prepared as a colloidal dispersion of NCs in hexane. The same synthesis protocol was followed for Sn-doped $\mathrm{In}_{2} \mathrm{O}_{3}$ NCs $\left(\mathrm{Sn}: \mathrm{In}_{2} \mathrm{O}_{3}\right)$ and $\mathrm{Sn}-\mathrm{Zr}$ codoped $\mathrm{In}_{2} \mathrm{O}_{3}\left(\mathrm{Sn}, \mathrm{Zr}: \mathrm{In}_{2} \mathrm{O}_{3}\right)$ NCs. The synthetic yield of all reactions lied in the $65-80 \%$ range.

For different $\mathrm{Zr}$ doping percentages, the amount of $\mathrm{Zr}$ and In precursor was varied accordingly. It is customary to note here that the incorporation of $\mathrm{Zr}$ in $\mathrm{In}_{2} \mathrm{O}_{3}$ has been found to be difficult under the aforementioned experimental conditions. With the slow-injection synthesis strategy adopted here, $\mathrm{Zr}$ doping efficiency was limited at approximately 25\%. Therefore, to synthesize $1.3 \% \mathrm{Zr}$-doped $\operatorname{In}_{2} \mathrm{O}_{3}$ $\left(\mathrm{Zr}: \mathrm{In}_{2} \mathrm{O}_{3}\right) \mathrm{NCs}, 0.25 \mathrm{mmol}$ of $\mathrm{Zr}(\mathrm{acac})_{4}$ was mixed with $4.75 \mathrm{mmol}$ of $\mathrm{In}(\mathrm{ac})_{3}$ in $10 \mathrm{~mL}$ oleic acid. Similar calculations can be performed for other $\mathrm{Zr}$ doping percentages in both $\mathrm{Zr}: \mathrm{In}_{2} \mathrm{O}_{3} \mathrm{NCs}$ and $\mathrm{Sn}, \mathrm{Zr}: \mathrm{In}_{2} \mathrm{O}_{3} \mathrm{NCs}$ while keeping in consideration that irrespective of the target composition, the total metal concentration in the solution should be $0.5 \mathrm{M}$. 


\section{Text S2: Nanocrystal Characterization}

X-ray diffraction (XRD): For determining the crystal structure and phase purity using XRD, assynthesized NCs were drop-casted on a small piece of Si wafer. Powder XRD patterns were then obtained through a Rigaku Miniflex 600 instrument operating in a Bragg-Brentano geometry with $\mathrm{Cu} \mathrm{K} \alpha(\lambda=$ $1.5406 \AA$ ) as the X-ray source. The same samples were also used in for X-ray photoelectron spectroscopy.

Raman Spectroscopy: Presence of an amorphous $\mathrm{ZrO}_{2} / \mathrm{In}_{2} \mathrm{O}_{3}$ phase and other impurities undetected in powder- XRD was checked via a Horiba LabRAM Aramis instrument equipped with confocal aperture. Samples were prepared by drop-casting a solution of $\mathrm{Zr}: \mathrm{In}_{2} \mathrm{O}_{3} \mathrm{NCs}$ on $2 \times 2$ glass slide followed by airdrying. All Raman spectra were obtained with a $\times 50$ microscope objective at an excitation wavelength of $532 \mathrm{~nm}$ and an acquisition time of $180 \mathrm{~s}$.

Transmission electron microscopy (TEM): Size and morphology of the NCs were examined using a low-resolution scanning TEM (STEM). Sample preparation for STEM involved drop-casting and subsequently air-drying $20 \mu \mathrm{L}$ dilute solution of NCs in hexane $(\sim 15 \mathrm{mg} / \mathrm{mL}$ of NCs in $1 \mathrm{~mL}$ hexane $)$ on copper TEM grid. STEM micrographs were obtained on a Hitachi S5500 operating at an accelerating voltage of $30 \mathrm{mV}$ in the STEM mode. The average diameter and standard deviation in sizes of different NCs were obtained by analyzing 100 particles from their respective STEM images using ImageJ software and fitting the statistics to a Gaussian size distribution. High-resolution TEM (HRTEM) images of the same NCs were obtained on a JEOL 2010F TEM operating at $200 \mathrm{kV}$ accelerating voltage.

Inductively coupled plasma-optical emission spectroscopy (ICP-OES): Doping percentages of $\mathrm{Zr}$ or $\mathrm{Sn}$ in $\mathrm{In}_{2} \mathrm{O}_{3}$ were experimentally attained by employing ICP-OES technique on a Varian 720-ES ICP Optical Emission Spectrometer. Samples for the ICP-OES were prepared by digesting 1-2 $\mathrm{mg}$ of the powder NCs in aqua-regia solution (a mixture of 35\% concentrated $\mathrm{HCl}$ and $70 \% \mathrm{HNO}_{3}$ in 3:1 ratio respectively) for 24 hours. This was followed by diluting the acid solution with milli-Q water such that the total acid concentration becomes approximately $2 \% \mathrm{v} / \mathrm{v}$. Standard solutions of variable concentration for different elements were prepared by diluting the commercial ICP-OES standard with $2 \% \mathrm{HNO}_{3}$ solution in milli-Q water.

X-ray photoelectron spectroscopy (XPS): To develop an understanding about the oxidation state of different elements and their doping percentages within the NCs, XPS spectra of different NCs were recorded on a Kratos X-ray Photoelectron Spectrometer - Axis Ultra DLD using a monochromatic Al Ka radiation $(\lambda=1486.6 \mathrm{eV})$ and a charge neutralizer. The XPS spectra obtained for different elements were carbon corrected by fixing the adventitious $\mathrm{C} 1 \mathrm{~s}$ peak to $284.8 \mathrm{eV}$ binding energy and analyzed through 
CasaXPS software. Doping percentages for $\mathrm{Zr}$ and/or Sn were calculated by taking a ratio of the integrated area under the $\mathrm{Zr} 3 \mathrm{~d}$ peak and/or Sn 3d peak with that under the In 3d, Zr 3d and Sn 3d XPS peaks while taking into consideration the sensitivity factors of the different elements involved.

Optical Spectroscopy: The absorption spectra of different NCs, which helped us to analyze the LSPR of different $\mathrm{Zr}: \mathrm{In}_{2} \mathrm{O}_{3}$ NCs were collected through Fourier transform infrared (FTIR) liquid cell in a Bruker Vertex 70 FTIR. The dispersion of NCs in tetrachloroethylene was injected through a syringe in the liquid cell between two infrared transparent $\mathrm{KBr}$ windows separated by a path length of $0.5 \mathrm{~mm}$. For highly doped $\mathrm{Sn}: \mathrm{In}_{2} \mathrm{O}_{3} \mathrm{NCs}$ and $\mathrm{Sn}, \mathrm{Zr}: \mathrm{In}_{2} \mathrm{O}_{3} \mathrm{NCs}$, near-infrared spectra were recorded in Agilent Cary 5000 spectrophotometer using a quartz cuvette with a path length of $10 \mathrm{~mm}$.
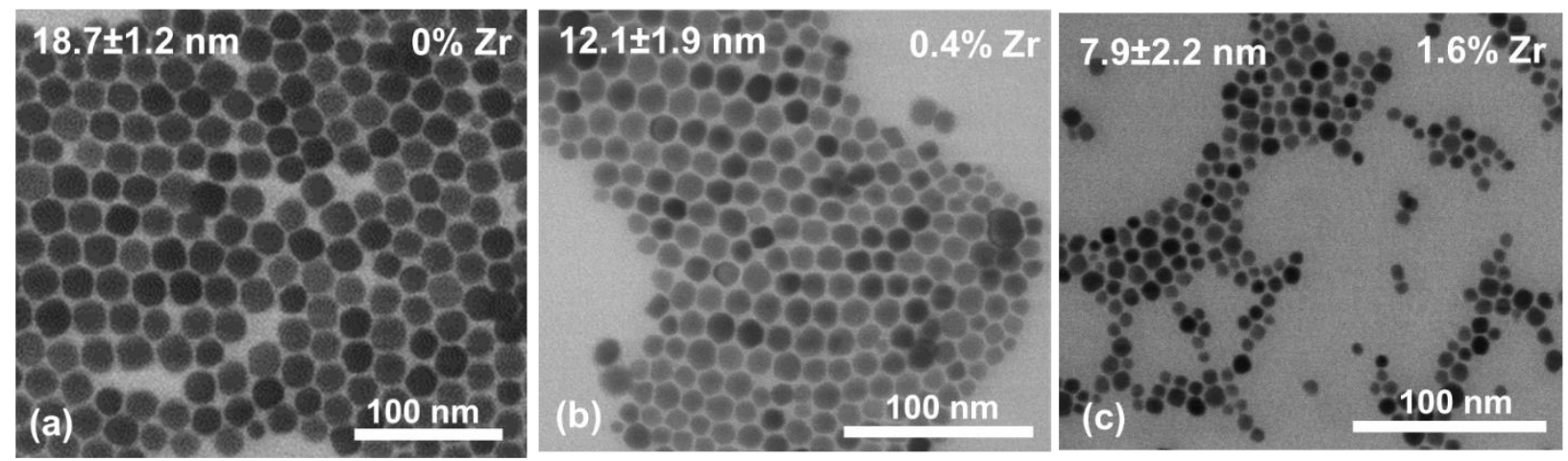

Figure S1: STEM images for different $\mathrm{Zr}: \mathrm{In}_{2} \mathrm{O}_{3} \mathrm{NCs}$. 

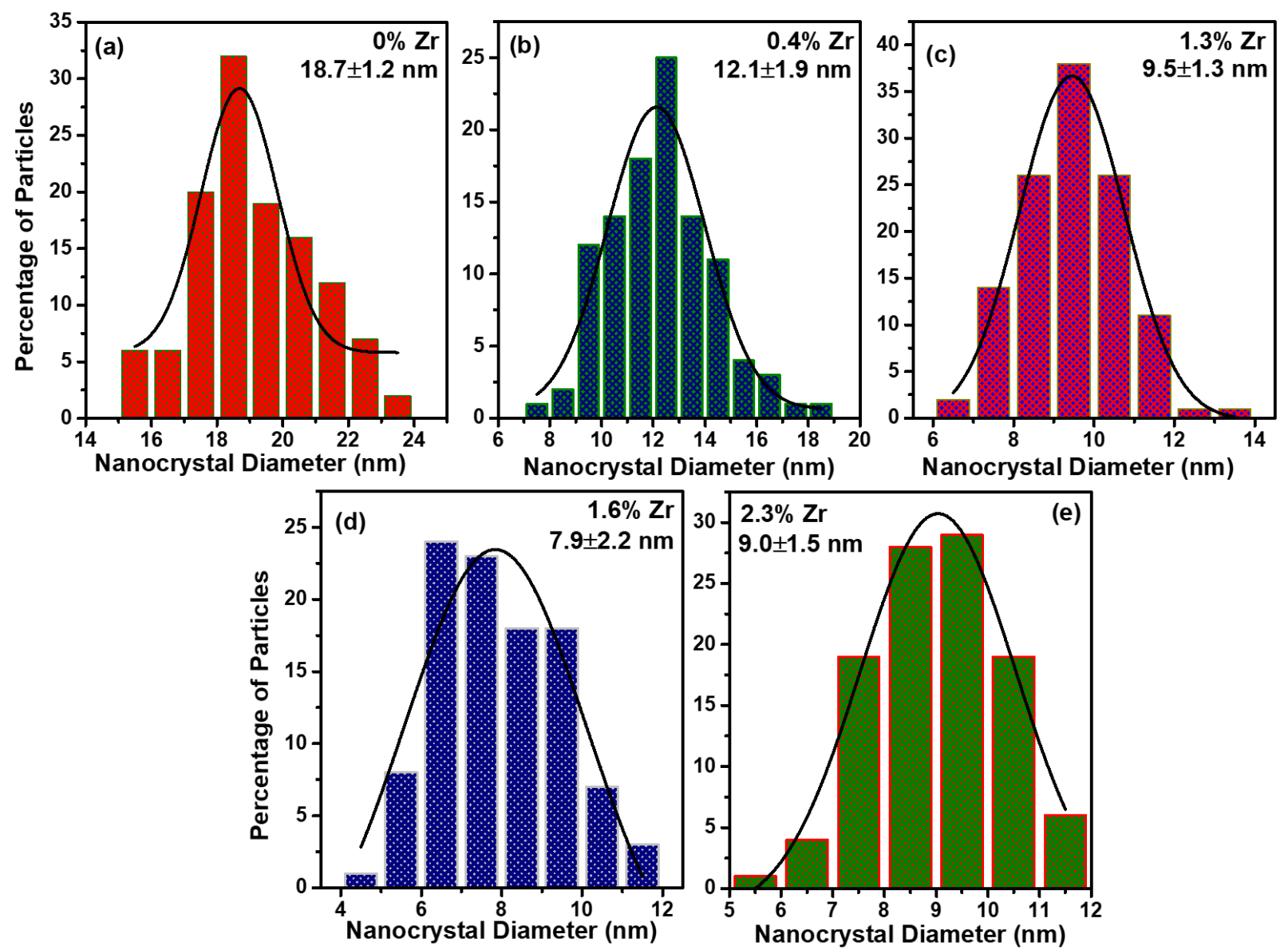

Figure S2: Size distribution plots of different $\mathrm{Zr}: \mathrm{In}_{2} \mathrm{O}_{3} \mathrm{NCs}$ obtained by analyzing particles from their representative STEM images in Figure 1c-d and Figure S1.

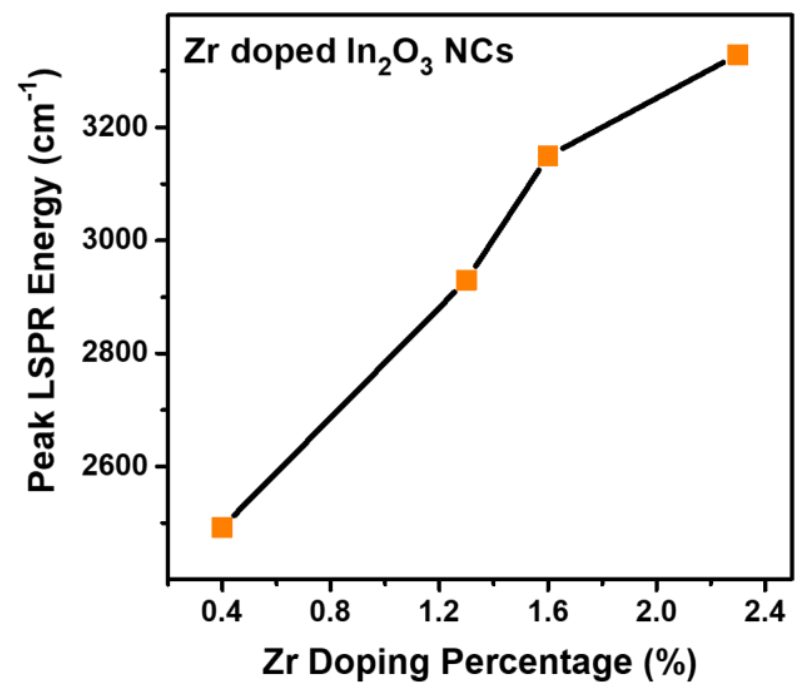

Figure S3: Variation in the peak LSPR energy of $\mathrm{Zr}: \operatorname{In}_{2} \mathrm{O}_{3}$ NCs with an increase in the $\mathrm{Zr}$ doping percentage. 
Table ST1: Tabulated experimental LSPR parameters of different NCs obtained from their optical extinction spectra.

\begin{tabular}{|c|c|c|c|}
\hline Composition & $\begin{array}{c}\text { LSPR Peak } \\
\text { Energy }\left(\mathbf{c m}^{-1}\right)\end{array}$ & $\begin{array}{c}\text { LSPR } \\
\text { FWHM (cm } \\
\mathbf{1})\end{array}$ & $\begin{array}{c}\text { LSPR } \\
\text { Q-Factor }\end{array}$ \\
\hline $0 \%$ Doping & 1296 & 648 & 2.0 \\
\hline $0.4 \% \mathrm{Zr}$ & 2492 & 870 & 2.9 \\
\hline $1.3 \% \mathrm{Zr}$ & 2930 & 735 & 4.0 \\
\hline $1.6 \% \mathrm{Zr}$ & 3149 & 936 & 3.4 \\
\hline $2.3 \% \mathrm{Zr}$ & 3329 & 840 & 4.0 \\
\hline $0.6 \% \mathrm{Sn}$ & 2001 & 1038 & 1.9 \\
\hline $2.8 \% \mathrm{Sn}$ & 4058 & 1188 & 3.4 \\
\hline $4.1 \% \mathrm{Sn}$ & 4732 & 1274 & 3.7 \\
\hline $7.5 \% \mathrm{Sn}$ & 5695 & 1204 & 4.7 \\
\hline $1.9 \% \mathrm{Sn}-0.9 \% \mathrm{Zr}$ & 3652 & 696 & 5.3 \\
\hline $0.9 \% \mathrm{Sn}-0.4 \% \mathrm{Zr}$ & 3026 & 860 & 3.5 \\
\hline $4.5 \% \mathrm{Sn}-0.8 \% \mathrm{Zr}$ & 4838 & 1071 & 4.6 \\
\hline $7.5 \% \mathrm{Sn}-1.0 \% \mathrm{Zr}$ & 5531 & 1066 & 5.3 \\
\hline
\end{tabular}


Table ST2: Comparison of the LSPR parameters and Q-factors of $\mathrm{Zr}: \operatorname{In}_{2} \mathrm{O}_{3}$ and $\mathrm{Sn}, \mathrm{Zr}: \mathrm{In}_{2} \mathrm{O}_{3}$ NCs with the benchmark materials for near and mid-infrared LSPR in the literature.

\begin{tabular}{|c|c|c|c|c|c|c|}
\hline Host & Dopant & $\begin{array}{c}\text { Doping } \\
\text { Level } \\
(\%)\end{array}$ & $\begin{array}{c}\text { LSPR } \\
\text { Peak } \\
\left(\mathrm{cm}^{-1}\right)\end{array}$ & $\begin{array}{c}\text { FWHM } \\
(\mathrm{meV})\end{array}$ & Q-factor & $\begin{array}{l}\text { Reference } \\
\text { Number }\end{array}$ \\
\hline $\mathrm{CdO}$ & $\mathrm{F}^{-}, \mathrm{In}^{3+}$ & $\sim 10,8.3$ & 5793 & 59 & 12.23 & 2 \\
\hline $\mathrm{CdO}$ & $\operatorname{In}^{3+}$ & 13.2 & 4415 & 67 & 8.15 & 3 \\
\hline $\mathrm{In}_{2} \mathrm{O}_{3}$ & $\mathrm{Sn}^{4+}, \mathrm{Cr}^{3+}$ & $6.6,23.8$ & 5717 & 99 & 7.2 & 4 \\
\hline $\mathrm{In}_{2} \mathrm{O}_{3}$ & $\mathrm{Zr}^{4+}, \mathrm{Sn}^{4+}$ & $0.9,1.9$ & 3652 & 86 & 5.3 & Present case \\
\hline $\mathrm{In}_{2} \mathrm{O}_{3}$ & $\mathrm{Zr}^{4+}, \mathrm{Sn}^{4+}$ & $1.0,7.5$ & 5531 & 132 & 5.3 & Present case \\
\hline $\mathrm{In}_{2} \mathrm{O}_{3}$ & $\mathrm{Sn}^{4+}$ & 6.4 & 5882 & $\sim 150$ & 4.85 & 5 \\
\hline $\mathrm{In}_{2} \mathrm{O}_{3}$ & $\mathrm{Zr}^{4+}$ & 1.3 & 2930 & 91 & 4.0 & Present case \\
\hline $\mathrm{In}_{2} \mathrm{O}_{3}$ & $\mathrm{Zr}^{4+}$ & 2.3 & 3329 & 104 & 4.0 & Present case \\
\hline $\mathrm{In}_{2} \mathrm{O}_{3}$ & $\mathrm{Ce}^{4+}$ & 5.2 & 2522 & 77 & 4.08 & 6 \\
\hline $\mathrm{ZnO}$ & $\mathrm{Al}^{3+}$ & 1.6 & $\sim 2500$ & $\sim 100$ & $3.9 *$ & 7 \\
\hline $\mathrm{Cu}_{2-\mathrm{x}} \mathrm{S}$ & $\mathrm{Cu}$ vacancy & $\sim 3$ & 5564 & 210 & 3.3 & 8 \\
\hline $\mathrm{WO}_{3-\mathrm{x}}$ & O vacancy & $\sim 5 \%$ & $\sim 11700$ & $\sim 900$ & 1.6 & 9 \\
\hline $\mathrm{ZnO}$ & $\mathrm{Ga}^{3+}$ & $\sim 2.5$ & $\sim 1667$ & - & $<1.0$ & 10 \\
\hline $\mathrm{TiO}_{2}$ & $\mathrm{Nb}^{5+}$ & 15.9 & $\sim 4000$ & $>450$ & $\sim 1$ & 11 \\
\hline
\end{tabular}

$*=$ Result obtained from single nanocrystal spectroscopy 


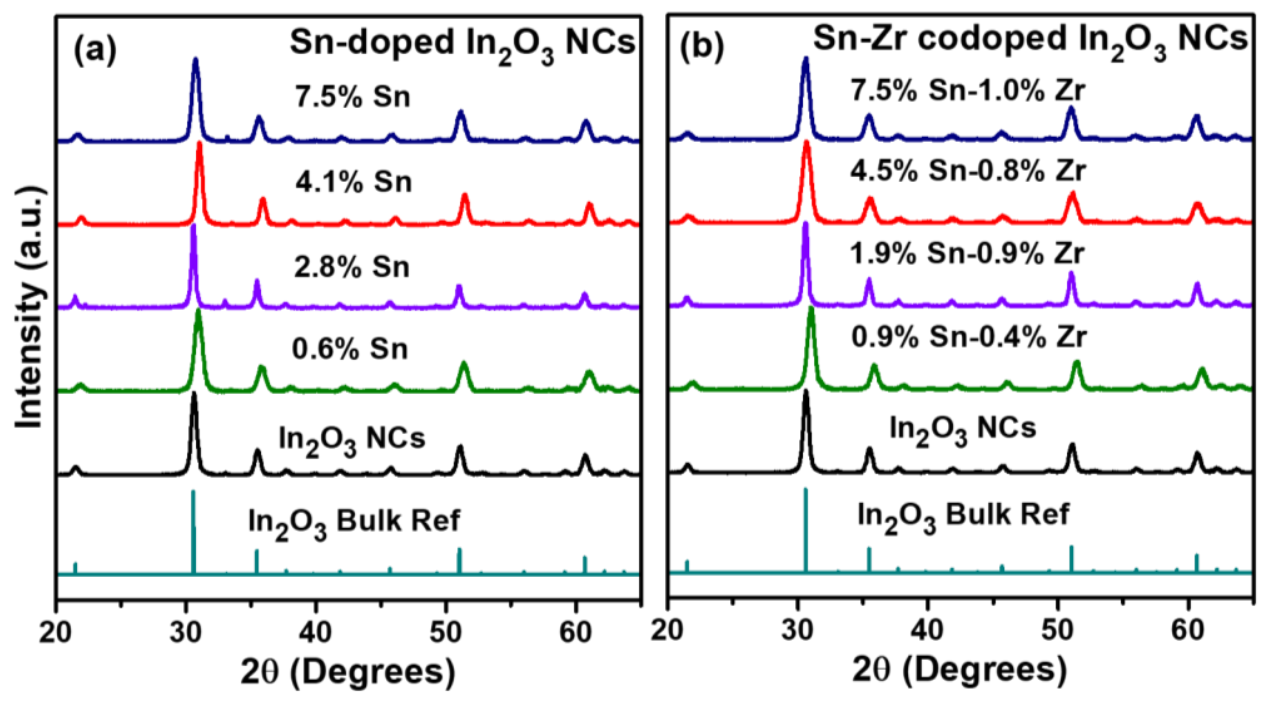

Figure S4: XRD patterns of (a) $\mathrm{Sn}: \operatorname{In}_{2} \mathrm{O}_{3}$ and, (b) $\mathrm{Sn}, \mathrm{Zr}: \operatorname{In}_{2} \mathrm{O}_{3} \mathrm{NCs}$ with reference to the bulk $\mathrm{In}_{2} \mathrm{O}_{3}$ reference (JCPDS 88-2160) showing the absence of any impurity phase and retention of the cubic bixbyite structure. 

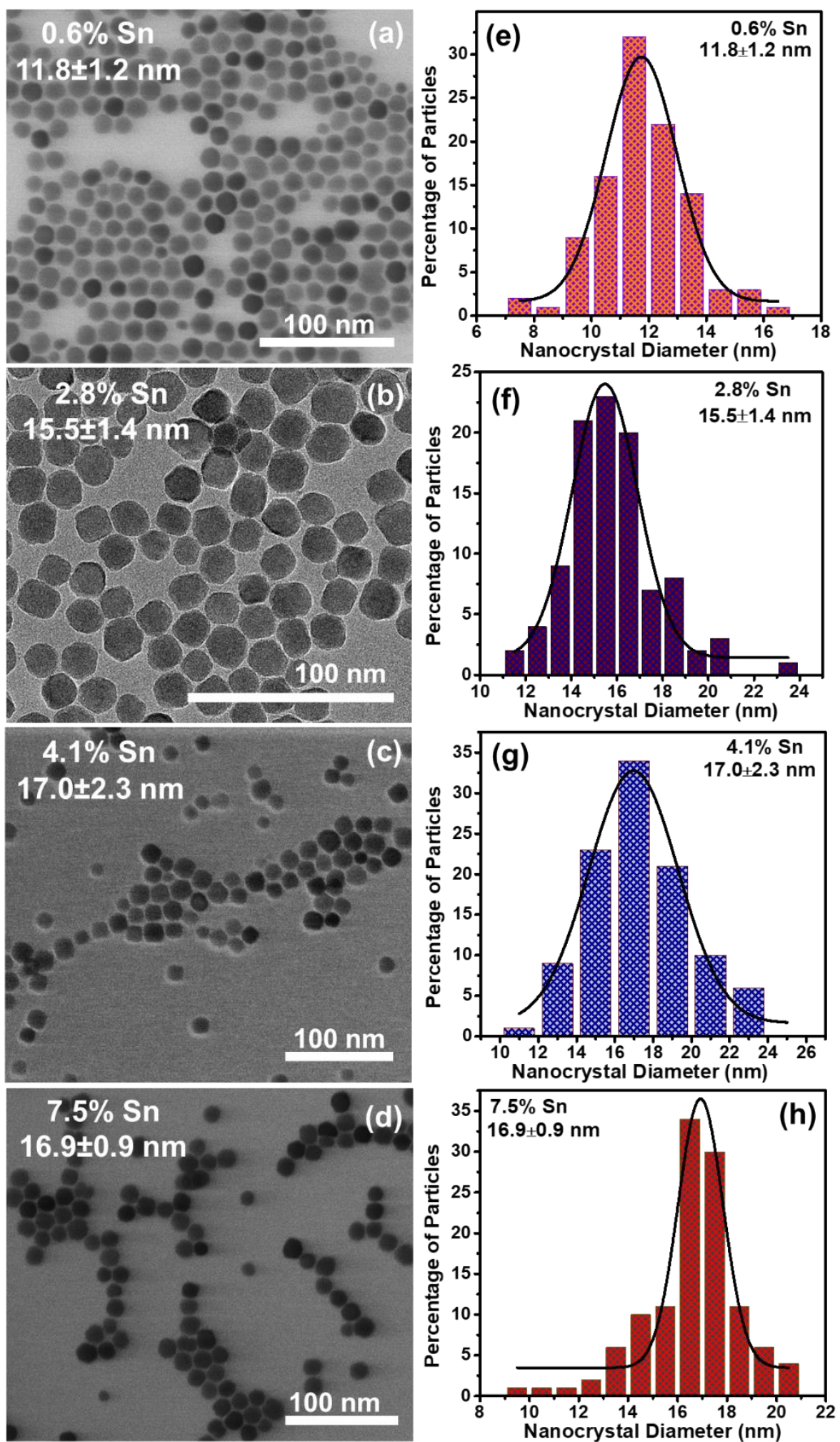

Figure S5: STEM images and size distribution curves (obtained by analyzing the diameter of particles) for $\mathrm{Sn}: \mathrm{In}_{2} \mathrm{O}_{3} \mathrm{NCs}$ with different $\mathrm{Sn}$ doping percentages. 

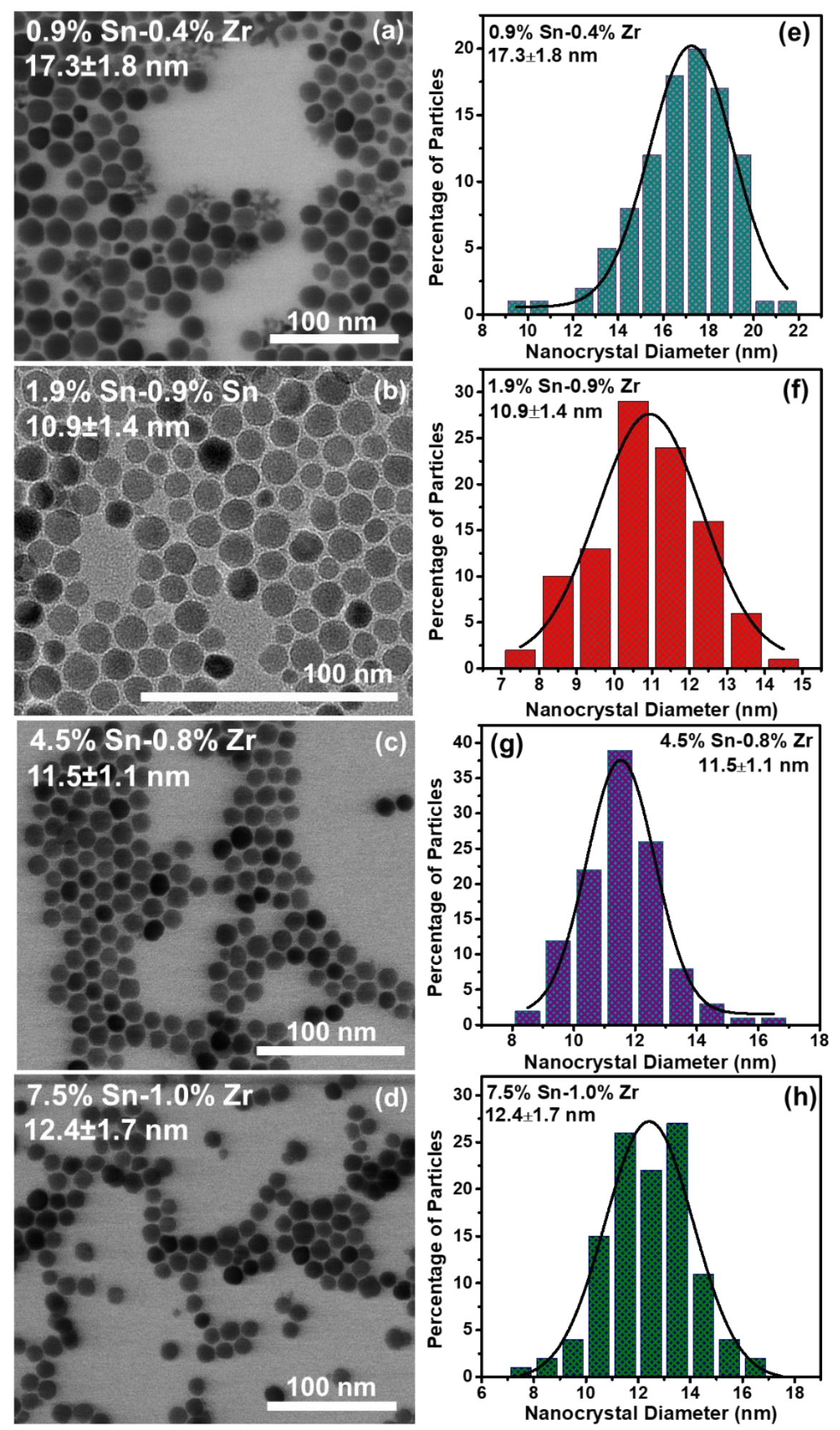

Figure S6: STEM images and size distribution curves (obtained by analyzing the diameter of particles) for $\mathrm{Sn}, \mathrm{Zr}: \mathrm{In}_{2} \mathrm{O}_{3} \mathrm{NCs}$ with different $\mathrm{Sn}$ doping percentages but an almost constant ( 1\%) $\mathrm{Zr}$ doping percentage. 


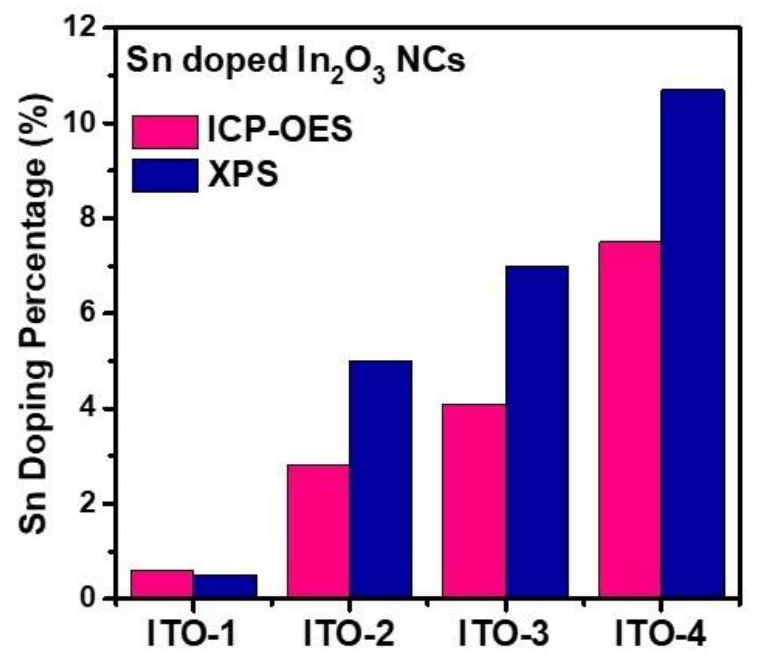

Figure S7: Correlation between the XPS and ICP-OES doping percentages of different $\mathrm{Sn}_{\mathrm{In}} \mathrm{In}_{2} \mathrm{O}_{3} \mathrm{NCs}$ establishing that the radial distribution of $\mathrm{Sn}$ is slightly surface segregated. The notations ITO-1 to ITO4 on the $\mathrm{x}$-axis just represents NCs with 4 different Sn doping percentages.
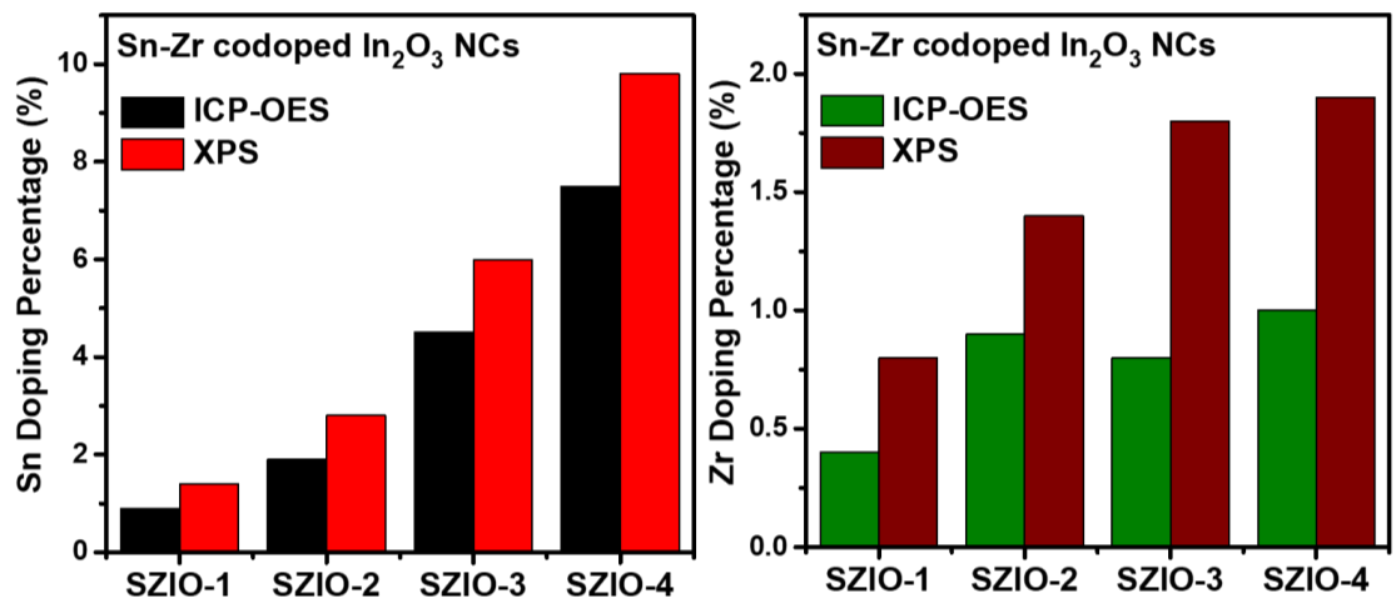

Figure S8: Correlation between the XPS and ICP-OES doping percentages of different $\mathrm{Sn}, \mathrm{Zr}: \mathrm{In}_{2} \mathrm{O}_{3} \mathrm{NCs}$ establishing that the radial distribution of $\mathrm{Sn}$, (a) is slightly surface segregated whereas that of $\mathrm{Zr}$, (b) is highly surface segregated. The notations SZIO-1 to SZIO-4 on the x-axis just represents NCs with 4 different compositions of $\mathrm{Sn}, \mathrm{Zr}$ codoped $\mathrm{In}_{2} \mathrm{O}_{3}$ NCs.

\section{Text S3: Simple Drude and extended Drude modeling of the optical extinction spectra}

The electric field of the incoming electromagnetic radiation interacts with the total electron density present in the material, in a form of light-matter interaction. The essence of polarization of conduction and valence band electrons by the external electric field is recorded by the complex dielectric function, which ultimately governs the optical properties of the material. Since LSPR derives only from conduction 
band electrons (free electrons), the frequency-dependent complex dielectric function $\varepsilon_{D}$ can be defined just by the contribution of free electrons, given by the simple Drude model

$$
\varepsilon_{D}(\omega)=\varepsilon_{\infty}-\frac{\omega_{p}^{2}}{\omega^{2}+i \omega \Gamma}
$$

Where $\varepsilon_{\infty}$ is the high-frequency dielectric constant for the material (taken as 3.9 for all NCs), $\omega_{P}$ is the bulk plasma frequency given by equation (2) and $\Gamma$ is the frequency-independent damping constant.

$$
\omega_{p}^{2}=\frac{n e^{2}}{\varepsilon_{0} m^{*}}
$$

here, $n$ is the free carrier density in the material $\left(\right.$ per $\left.\mathrm{cm}^{-3}\right), e$ is the electronic charge, $\varepsilon_{0}$ is the dielectric permittivity of vacuum, and $m *$ is the effective mass of the carriers.

However, the simple Drude model is valid only when the damping of charge carriers occurs by a frequency-independent mechanism such as electron-electron scattering, electron-photon scattering, surface scattering, or phonon-phonon scattering as in noble metal NCs. In doped semiconductors it is often necessary to also consider ionized impurity scattering where the electric field experienced by the charge carrier is much different above and below the bulk plasma frequency. ${ }^{12,13}$

To take into account the frequency-dependent scattering of charge carriers, an extended Drude model is employed where the essence of frequency-dependent carrier scattering is considered through an empirical equation

$$
\Gamma(\omega)=\Gamma_{L}-\frac{\Gamma_{L}-\Gamma_{H}}{\pi}\left[\tan ^{-1}\left(\frac{\omega-\Gamma_{X}}{\Gamma_{W}}\right)+\frac{\pi}{2}\right]
$$

here $\Gamma(\omega)$ in the extended Drude model is the frequency-dependent analogue of the $\Gamma$ (frequencyindependent) in the simple Drude model. $\Gamma_{L}$ and $\Gamma_{H}$ are the low-frequency and high-frequency damping constants respectively, $\Gamma_{X}$ is the crossover-frequency from the low to high frequency region and $\Gamma_{W}$ is the width of the crossover region. ${ }^{5}$

On a different note, the electric field at the surface of a NC extends to the space around it. Since NCs are well-separated from each other in a dilute solution, any near-field interaction between them can be negated, however, one can't completely rule out far-field interactions between NCs and, interactions between the NCs and the solvent molecules. These interactions change the overall dielectric environment around the NCs thereby modifying their optical response to the incident electromagnetic radiation. We 
employed Maxwell-Garnett effective medium approximation (MG-EMA), which neglects near-field interactions between adjacent NCs (electronically linked to each other) but takes into account the far-field interactions between NCs and interaction between the NCs and the solvent molecules. Using MG-EMA, the effective dielectric function $\varepsilon_{e f f}$ is given by, ${ }^{14}$

$$
\frac{\varepsilon_{e f f}-\varepsilon_{H}}{\varepsilon_{e f f}+2 \varepsilon_{H}}=f_{v} \frac{\varepsilon_{D}-\varepsilon_{H}}{\varepsilon_{D}+2 \varepsilon_{H}}
$$

where $\varepsilon_{H}$ is the dielectric medium of the solvent (2.26 for tetrachloroethylene), $f_{v}$ is the volume fraction of NCs in the solution, and $\varepsilon_{D}$ is the complex dielectric function of the material as described in equation (1). From equation (4), the absorbance of the solution can be approximated as $4 \pi \operatorname{Im}\left(\left\{\varepsilon_{e f f}\right\}^{1 / 2}\right)$ where $\operatorname{Im}$ $\left(\varepsilon_{e f f}\right)$ is the imaginary quotient of the effective dielectric function.

The MATLAB code developed by us combines

a) Equations (1)-(3) for simple Drude model considering $\omega_{P}, \Gamma$ and $f_{v}$ as floating parameters.

b) Equations (1)-(4) for extended Drude model considering $\omega_{P}, \Gamma_{L}, \Gamma_{H}, \Gamma_{X}, \Gamma_{w}$ and $f_{v}$ as floating parameters, to model the absorbance of our NC solution. Multiple fits were performed for each sample to ensure that the parameter values obtained after fitting do not deviate drastically between different fits.

$\omega_{P}$ can then be used to calculate the free electron density in the NCs. We note here that for calculating the electron density, we used an effective carrier mass of $0.22 \mathrm{~m}_{\mathrm{e}}$ for $\mathrm{Zr}: \mathrm{In}_{2} \mathrm{O}_{3} \mathrm{NCs}$ as suggested by Xu et. al. ${ }^{15}$ and $0.39 \mathrm{~m}_{\mathrm{e}}$ for $\mathrm{Sn}: \mathrm{In}_{2} \mathrm{O}_{3}$ and $\mathrm{Sn}, \mathrm{Zr}: \mathrm{In}_{2} \mathrm{O}_{3}$ NCs. Moreover, using the respective effective masses, one can optically derive DC mobility ( $\mu_{\mathrm{opt}}$ ) of charge carriers in the material using equation 5 .

$$
\mu_{o p t}=\frac{e}{m^{*} \Gamma}
$$

Even though the above equation is valid only for the simple Drude model (DC mobility has zero frequency and hence no frequency dependence), one can also employ it for the extended Drude model by using $\Gamma(0)$ from equation (3), i.e. damping constant at zero frequency. Average values of different parameters along with their standard deviation obtained from the extended Drude and simple Drude model have been tabulated in Table ST3 and Table ST4 respectively. 
Table ST3: Parameters obtained through fits of optical extinction spectra by the extended Drude model. Electron density and optical electron mobility have been calculated from the fitting parameters using equations (1) and (5) in the main manuscript, respectively.

\begin{tabular}{|c|c|c|c|c|c|c|c|}
\hline Composition & $\begin{array}{c}\omega \mathbf{P} \\
\left(\mathrm{cm}^{-1}\right)\end{array}$ & $\begin{array}{c}\mathrm{N} \\
\left(10^{20}\right. \\
\left.\mathrm{cm}^{-3}\right) \\
\end{array}$ & $\begin{array}{c}\Gamma_{\mathrm{L}} \\
\left(\mathrm{cm}^{-1}\right)\end{array}$ & $\begin{array}{c}\Gamma_{\mathbf{H}} \\
\left(\mathbf{c m}^{-1}\right)\end{array}$ & $\begin{array}{c}\Gamma \mathbf{X} \\
\left(\mathbf{c m}^{-1}\right)\end{array}$ & $\begin{array}{c}\Gamma \mathrm{W} \\
\left(\mathbf{c m}^{-1}\right)\end{array}$ & $\begin{array}{c}\begin{array}{c}\mu_{\mathrm{opt}} \\
\left(\mathrm{cm}^{2} / \mathrm{V}\right.\end{array} \\
\mathrm{s})\end{array}$ \\
\hline 0\% Doping & $3880 \pm 2$ & 0.37 & $389 \pm 59$ & $841 \pm 23$ & $1269 \pm 85$ & $441 \pm 63$ & $97.7 \pm 9.4$ \\
\hline $0.4 \% \mathrm{Zr}$ & $7290 \pm 1$ & 1.31 & $872 \pm 3$ & $536 \pm 3$ & $2996 \pm 4$ & $22.0 \pm 5$ & $48.7 \pm 0.2$ \\
\hline $1.3 \% \mathrm{Zr}$ & $8535 \pm 1$ & 1.79 & $725 \pm 4$ & $1324 \pm 2$ & $6021 \pm 33$ & $48 \pm 24$ & $58.4 \pm 0.3$ \\
\hline $1.6 \% \mathrm{Zr}$ & $8970 \pm 4$ & 1.98 & $1196 \pm 5$ & $617 \pm 6$ & $3274 \pm 14$ & $326 \pm 11$ & $35.9 \pm 0.1$ \\
\hline $2.3 \% \mathrm{Zr}$ & $9572 \pm 2$ & 2.25 & $1035 \pm 23$ & $682 \pm 22$ & $3393 \pm 20$ & $162 \pm 29$ & $41.2 \pm 0.9$ \\
\hline $0.6 \% \mathrm{Sn}$ & $6027 \pm 4$ & 1.58 & $1109 \pm 1$ & $767 \pm 7$ & $3780 \pm 20$ & $62 \pm 10$ & $21.6 \pm 0.1$ \\
\hline $2.8 \% \mathrm{Sn}$ & $11719 \pm 5$ & 5.98 & $1718 \pm 200$ & $853 \pm 85$ & $3926 \pm 231$ & $808 \pm 336$ & $14.5 \pm 1.4$ \\
\hline $4.1 \% \mathrm{Sn}$ & $13626 \pm 3$ & 8.08 & $1437 \pm 34$ & $611 \pm 83$ & $5318 \pm 117$ & $448 \pm 129$ & $16.9 \pm 0.1$ \\
\hline $7.5 \% \mathrm{Sn}$ & $16624 \pm 1$ & 12.0 & $1247 \pm 9$ & $611 \pm 29$ & $7261 \pm 27$ & $202 \pm 46$ & $19.3 \pm 0.1$ \\
\hline $\begin{array}{l}1.9 \% \mathrm{Sn}- \\
0.9 \% \mathrm{Zr}\end{array}$ & $10778 \pm 1$ & 5.06 & $661 \pm 9$ & $2319 \pm 164$ & $7436 \pm 49$ & $135 \pm 55$ & $35.6 \pm 0.3$ \\
\hline $\begin{array}{c}0.9 \% \mathrm{Sn}^{-} \\
0.4 \% \mathrm{Zr}\end{array}$ & $8876 \pm 2$ & 3.43 & $745 \pm 7$ & $886 \pm 3$ & $2892 \pm 9$ & $55 \pm 8$ & $32.1 \pm 0.3$ \\
\hline $\begin{array}{c}4.5 \% \mathrm{Sn}^{-} \\
0.8 \% \mathrm{Zr}\end{array}$ & $14156 \pm 2$ & 8.72 & $579 \pm 14$ & $1060 \pm 8$ & $4306 \pm 4$ & $98 \pm 19$ & $41.1 \pm 0.8$ \\
\hline $\begin{array}{l}7.5 \% \mathrm{Sn}^{-} \\
1.0 \% \mathrm{Zr}\end{array}$ & $16240 \pm 3$ & 11.5 & $856 \pm 14$ & $1103 \pm 11$ & $5329 \pm 18$ & $136 \pm 12$ & $27.9 \pm 0.4$ \\
\hline
\end{tabular}


Table ST4: Parameters obtained through the fitting of the optical extinction spectra using the simple Drude model. Electron density and optical electron mobilities were obtained by substituting the fitting parameters in equation (1) and equation (5), respectively.

\begin{tabular}{|c|c|c|c|c|}
\hline Composition & $\begin{array}{c}\boldsymbol{\omega} \mathbf{P} \\
\left(\mathbf{c m}^{-1}\right)\end{array}$ & $\begin{array}{c}\mathbf{N} \\
\left(\mathbf{1 0} \mathbf{c m}^{-3}\right)\end{array}$ & $\begin{array}{c}\boldsymbol{\Gamma} \\
\left(\mathbf{c m}^{-1}\right)\end{array}$ & $\begin{array}{c}\boldsymbol{\mu}_{\mathbf{o p t}} \\
\left(\mathbf{c m}^{\mathbf{2}} \mathbf{\mathbf { V } . \mathbf { s }}\right)\end{array}$ \\
\hline $0 \%$ Doping & 3879 & 0.37 & 680 & 62.4 \\
\hline $0.4 \% \mathrm{Zr}$ & 7260 & 1.29 & 790 & 53.7 \\
\hline $1.3 \% \mathrm{Zr}$ & 8516 & 1.78 & 752 & 56.4 \\
\hline $1.6 \% \mathrm{Zr}$ & 8998 & 1.99 & 932 & 45.5 \\
\hline $2.3 \% \mathrm{Zr}$ & 9597 & 2.26 & 905 & 46.9 \\
\hline $0.6 \% \mathrm{Sn}$ & 6020 & 1.58 & 1074 & 22.3 \\
\hline $2.8 \% \mathrm{Sn}$ & 11745 & 6.0 & 1219 & 19.6 \\
\hline $4.1 \% \mathrm{Sn}$ & 13613 & 8.06 & 1221 & 19.6 \\
\hline $7.5 \% \mathrm{Sn}$ & 16613 & 12.0 & 1198 & 19.9 \\
\hline $1.9 \% \mathrm{Sn}-0.9 \% \mathrm{Zr}$ & 10780 & 5.06 & 686 & 34.9 \\
\hline $0.9 \% \mathrm{Sn}-0.4 \% \mathrm{Zr}$ & 8865 & 3.42 & 860 & 27.8 \\
\hline $4.5 \% \mathrm{Sn}-0.8 \% \mathrm{Zr}$ & 14185 & 8.76 & 960 & 24.8 \\
\hline $7.5 \% \mathrm{Sn}-1.0 \% \mathrm{Zr}$ & 16228 & 11.5 & 1022 & 23.4 \\
\hline
\end{tabular}



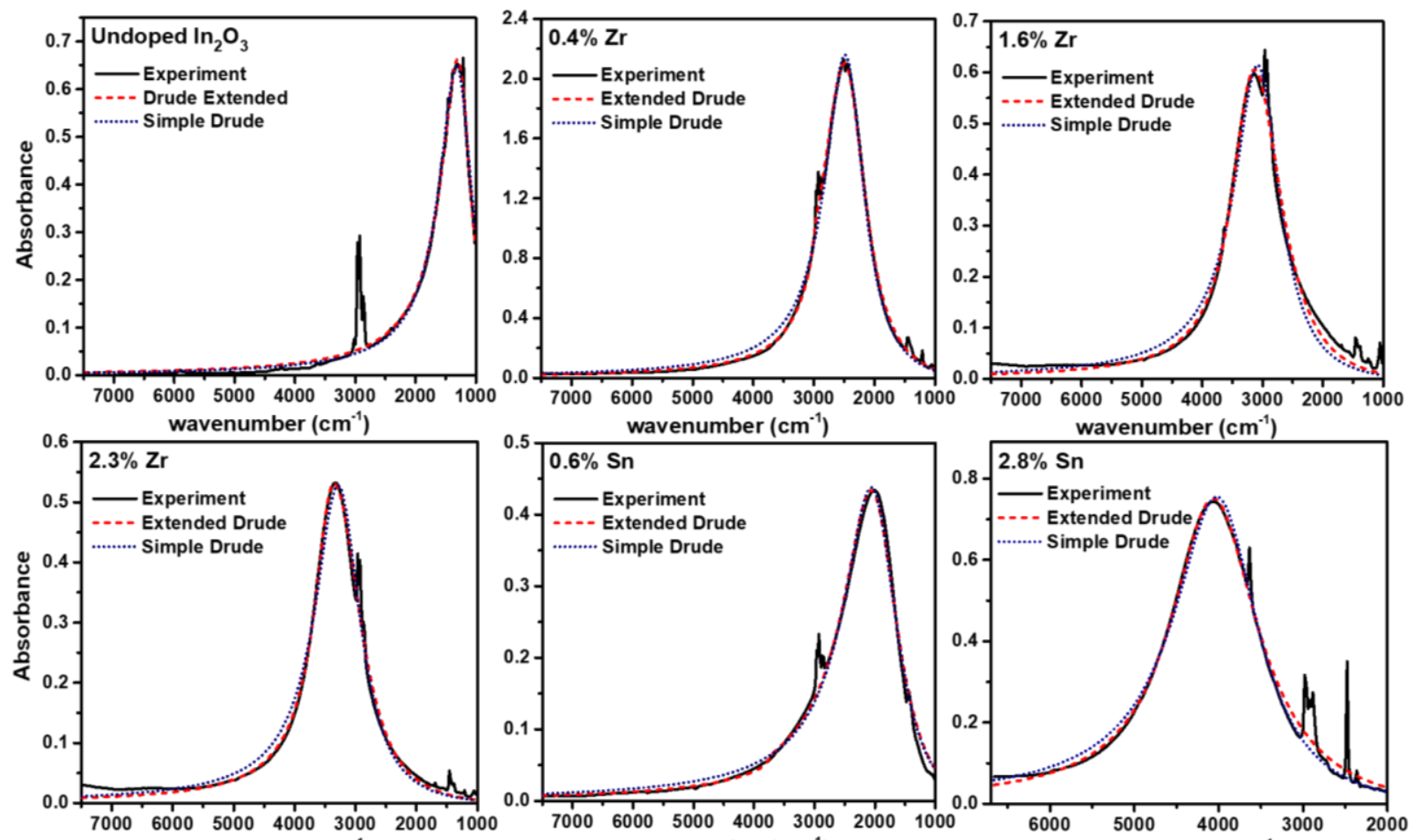

wavenumber $\left(\mathrm{cm}^{-1}\right)$

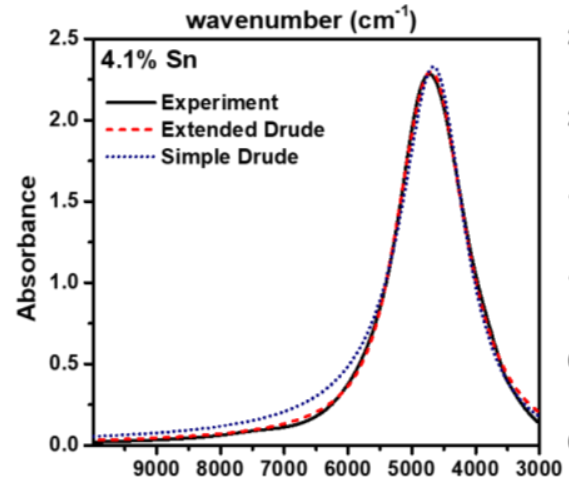
wavenumber $\left(\mathrm{cm}^{-1}\right)$
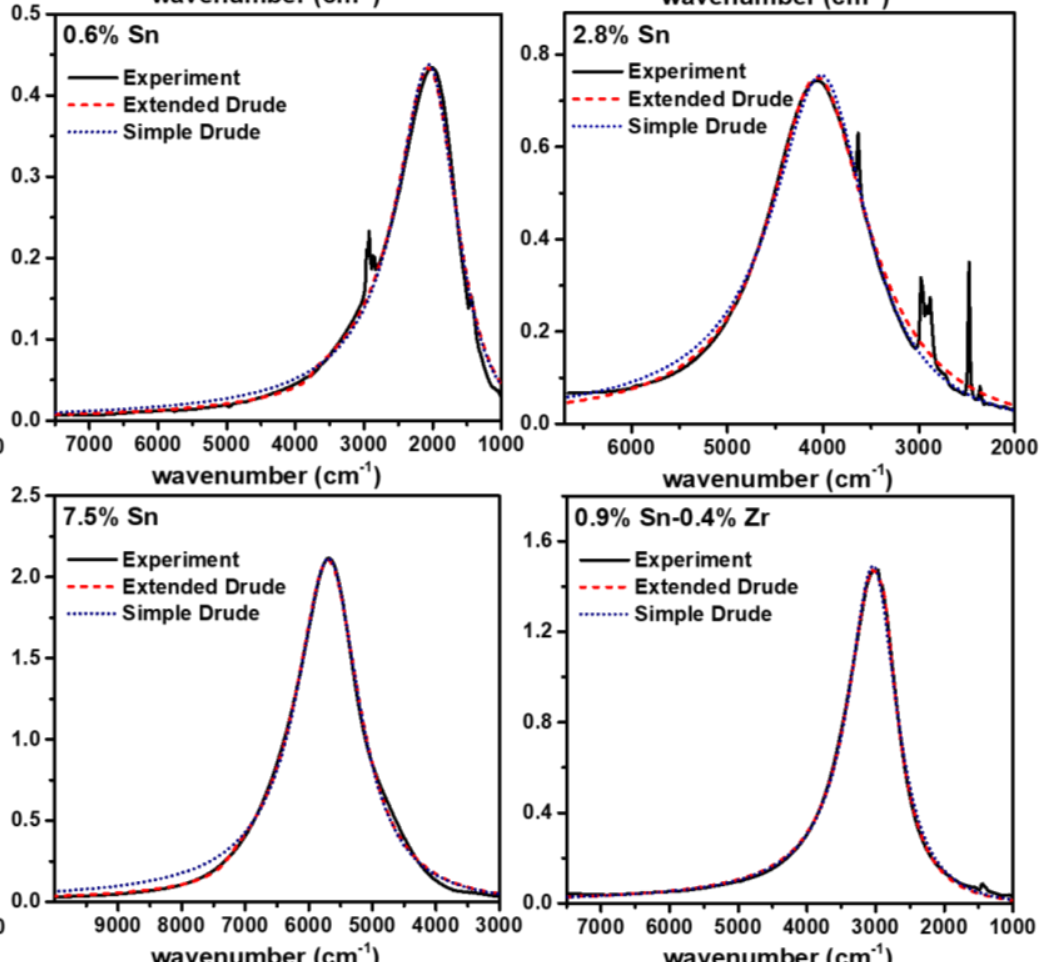
wavenumber $\left(\mathrm{cm}^{-1}\right)$

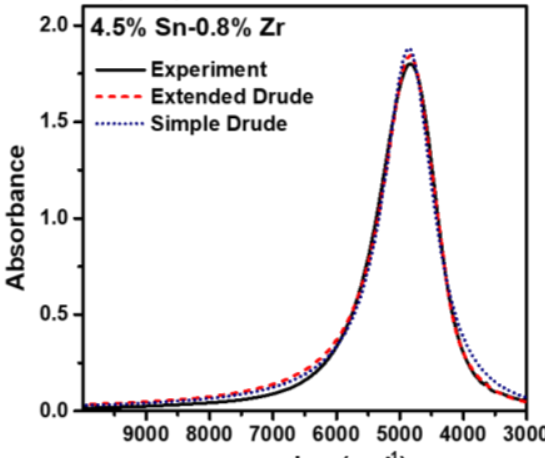
wavenumber $\left(\mathrm{cm}^{-1}\right)$ wavenumber $\left(\mathrm{cm}^{-1}\right)$

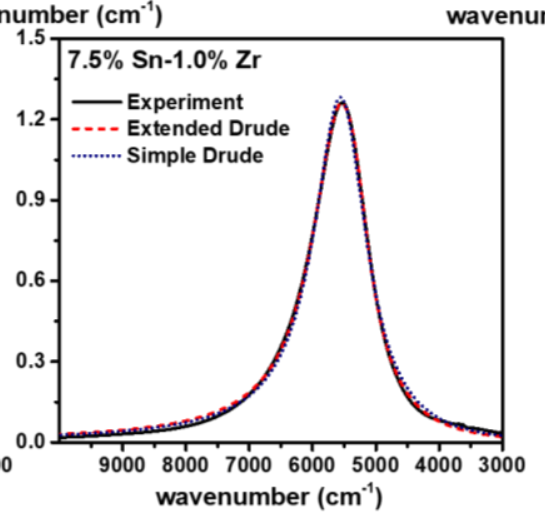

Figure S9: Simple Drude and extended Drude model fits to the optical extinction spectra of different $\mathrm{Zr}: \mathrm{In}_{2} \mathrm{O}_{3}, \mathrm{Sn}: \mathrm{In}_{2} \mathrm{O}_{3}$ and $\mathrm{Sn}, \mathrm{Zr}: \mathrm{In}_{2} \mathrm{O}_{3} \mathrm{NCs}$. 

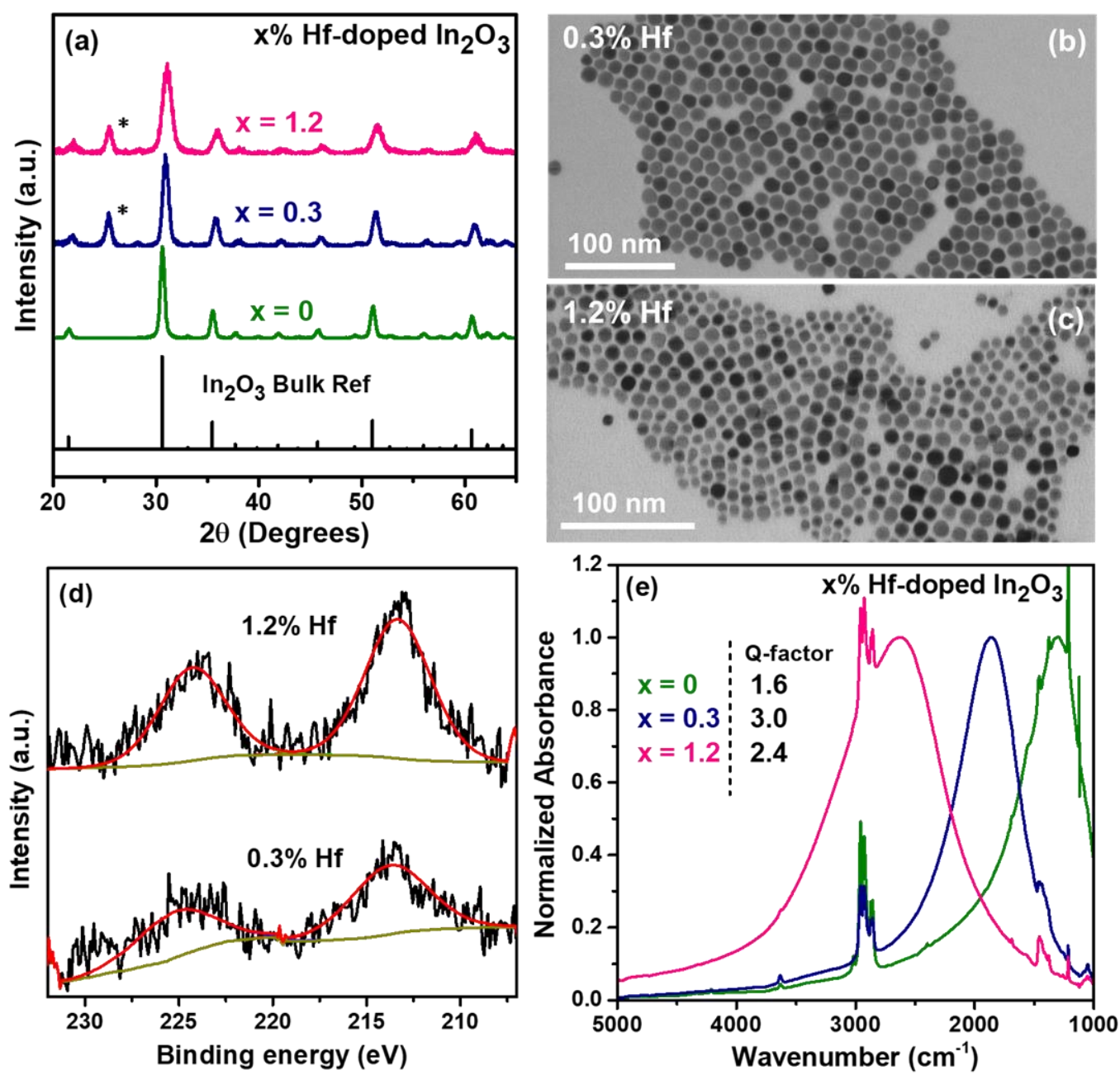

Figure S10: Hf-doped $\operatorname{In}_{2} \mathrm{O}_{3}$ (Hf: $\left.\operatorname{In}_{2} \mathrm{O}_{3}\right)$ NCs as an example of the dopant selection strategy. Since both the chemical and physical properties of $\mathrm{Hf}$ and $\mathrm{Zr}$ are very similar due to lanthanide contraction, $\mathrm{Hf}$ doping in the $\operatorname{In}_{2} \mathrm{O}_{3}$ lattice is also expected to generate LSPR similar to $\mathrm{Zr}$, as shown in the main manuscript. (a) Comparison of XRD patterns of Hf: $\operatorname{In}_{2} \mathrm{O}_{3}$ NCs with undoped $\operatorname{In}_{2} \mathrm{O}_{3}$ NCs and bulk reference (JCPDS 882160) shows retention of the cubic bixbyite phase, absence of any impurity and a gradual shift in diffraction peak with increase in Hf doping percentage. Peaks marked with an asterisk (*) are due to the substrate. (b-c) STEM micrographs of Hf: $\operatorname{In}_{2} \mathrm{O}_{3}$ NCs (d) XPS spectra of Hf 3d for Hf: $\operatorname{In}_{2} \mathrm{O}_{3}$ NCs showing binding energy peaks corresponding to +4 oxidation state of $\mathrm{Hf}$ and theoretical peak fit depicting the presence of single oxidation state. (e) Optical extinction spectra of $\mathrm{Hf}: \mathrm{In}_{2} \mathrm{O}_{3} \mathrm{NCs}$ showing narrow LSPR bands increasing in energy with an increase in the Hf doping concentration. 


\section{References:}

1. Jansons, A. W.; Hutchison, J. E., Continuous Growth of Metal Oxide Nanocrystals: Enhanced Control of Nanocrystal Size and Radial Dopant Distribution. ACS Nano 2016, 10, 6942-6951.

2. Ye, X.; Fei, J.; Diroll, B. T.; Paik, T.; Murray, C. B., Expanding the Spectral Tunability of Plasmonic Resonances in Doped Metal-Oxide Nanocrystals through Cooperative Cation-Anion Codoping. J. Am. Chem. Soc. 2014, 136, 11680-11686.

3. Gordon, T. R.; Paik, T.; Klein, D. R.; Naik, G. V.; Caglayan, H.; Boltasseva, A.; Murray, C. B., ShapeDependent Plasmonic Response and Directed Self-Assembly in a New Semiconductor Building Block, Indium-Doped Cadmium Oxide (ICO). Nano Lett. 2013, 13, 2857-2863.

4. Tandon, B.; Yadav, A.; Khurana, D.; Reddy, P.; Santra, P. K.; Nag, A., Size-Induced Enhancement of Carrier Density, LSPR Quality Factor, and Carrier Mobility in $\mathrm{Cr}-\mathrm{Sn}$ Doped $\mathrm{In}_{2} \mathrm{O}_{3}$ Nanocrystals. Chem. Mater. 2017, 29, 9360-9368.

5. Lounis, S. D.; Runnerstrom, E. L.; Bergerud, A.; Nordlund, D.; Milliron, D. J., Influence of Dopant Distribution on the Plasmonic Properties of Indium Tin Oxide Nanocrystals. J. Am. Chem. Soc. 2014, 136, 7110-7116.

6. Runnerstrom, E. L.; Bergerud, A.; Agrawal, A.; Johns, R. W.; Dahlman, C. J.; Singh, A.; Selbach, S. M.; Milliron, D. J., Defect Engineering in Plasmonic Metal Oxide Nanocrystals. Nano Lett. 2016, 16, 3390-3398.

7. Johns, R. W.; Bechtel, H. A.; Runnerstrom, E. L.; Agrawal, A.; Lounis, S. D.; Milliron, D. J., Direct Observation of Narrow Mid-Infrared Plasmon Linewidths of Single Metal Oxide Nanocrystals. Nat. Commun. 2016, 7, 11583.

8. Luther, J. M.; Jain, P. K.; Ewers, T.; Alivisatos, A. P., Localized surface plasmon resonances arising from free carriers in doped quantum dots. Nat. Mater. 2011, 10, 361-366.

9. Manthiram, K.; Alivisatos, A. P., Tunable Localized Surface Plasmon Resonances in Tungsten Oxide Nanocrystals. J. Am. Chem. Soc. 2012, 134, 3995-3998.

10. Della Gaspera, E.; Bersani, M.; Cittadini, M.; Guglielmi, M.; Pagani, D.; Noriega, R.; Mehra, S.; Salleo, A.; Martucci, A., Low-Temperature Processed Ga-Doped ZnO Coatings from Colloidal Inks. $J$. Am. Chem. Soc. 2013, 135, 3439-3448.

11. De Trizio, L.; Buonsanti, R.; Schimpf, A. M.; Llordes, A.; Gamelin, D. R.; Simonutti, R.; Milliron, D. J., Nb-Doped Colloidal $\mathrm{TiO}_{2}$ Nanocrystals with Tunable Infrared Absorption. Chem. Mater. 2013, 25, 3383-3390.

12. Mendelsberg, R. J.; Garcia, G.; Li, H.; Manna, L.; Milliron, D. J., Understanding the Plasmon Resonance in Ensembles of Degenerately Doped Semiconductor Nanocrystals. J. Phys. Chem. C 2012, 116, 12226-12231.

13. Lounis, S. D.; Runnerstrom, E. L.; Llordés, A.; Milliron, D. J., Defect Chemistry and Plasmon Physics of Colloidal Metal Oxide Nanocrystals. J. Phys. Chem. Lett. 2014, 5, 1564-1574.

14. Ghosh, S. K.; Pal, T., Interparticle Coupling Effect on the Surface Plasmon Resonance of Gold Nanoparticles: From Theory to Applications. Chem. Rev. 2007, 107, 4797-4862.

15. Xu, J.; Liu, J. B.; Liu, B. X.; Li, S. N.; Wei, S. H.; Huang, B., Design of n-Type Transparent Conducting Oxides: The Case of Transition Metal Doping in $\mathrm{In}_{2} \mathrm{O}_{3}$. Adv. Electron. Mater. 2018, 4, 1700553. 